\title{
ESTRUCTURA ECONÓMICA MEXICANA: SECTORES CLAVES, ESTRATÉGICOS, IMPULSORES E INDEPENDIENTES 2012
}

MEXICAN ECONOMIC STRUCTURE: KEY, STRATEGIC, DRIVERS AND INDEPENDENT SECTORS 2012

Gabriela Araceli Cardona
Reséndiz
Instituto Politécnico NACIONAL,
MÉXICO
gaby.cardona@live.com

Manuel Alejandro Cardenete Flores

UNIVERSIDAD LOYOLA, ESPAÑA

macardenete@uloyola.es
Claudia Icela Martínez García $^{1}$

Instituto Politécnico Nacional, MÉXICO

claimar.garcia@outlook.com

\section{RESUMEN}

El diseño de políticas económicas para incentivar el crecimiento económico hace necesaria la identificación de sectores productivos clave para encaminar adecuadamente los esfuerzos de política pública. El objetivo del presente trabajo es identificar dichos sectores productivos mediante la utilización de modelos de equilibrio general aplicado. Primero se construyó la matriz de contabilidad social para México 2012; posteriormente se realizó un análisis de multiplicadores generalizados y para finalizar, con base en la matriz de contabilidad social, se determinaron los efectos de absorción y difusión para ubicar a los sectores clave, estratégicos, impulsores

1 Agradecemos las observaciones de los dictaminadores anónimos que han enriquecido el presente trabajo.

Recepción: 5 de enero de 2018 Aceptación: 7 de marzo de 2018
Revista de Economía - Vol. XXXV - Núm 90

Enero a Junio de 2018 - Págs.: 9-50 
e independientes. Como resultado del análisis los sectores que tienen un mayor efecto multiplicador son el de servicios educativos, actividades legislativas y el corporativo. Por otra parte, los sectores clave son el comercio y los servicios inmobiliarios; los estratégicos la manufactura y transporte; mientras que las actividades legislativas y corporativos son sectores impulsores, finalmente, la agricultura y la construcción son sectores independientes.

Palabras clave: sectores estratégicos, matriz de contabilidad social, efecto multiplicador.

JEL: O10, O20, O49

\begin{abstract}
The design of economic policies to encourage economic growth makes it necessary to identify key productive sectors to adequately channel public policy efforts. The objective of this paper is to identify these productive sectors through the use of applied general equilibrium models. First, the social accounting matrix for Mexico 2012 was built. Subsequently, an analysis of generalized multipliers was carried out. Finally, based on the social accounting matrix, the effects of absorption and diffusion were determined to locate the key, strategic, driving and independent sectors. As a result of the analysis, the sectors that have a greater multiplier effect are the education services sector, legislative activities and the corporate sector. On the other hand, the key sectors are trade and real estate services, the strategic ones are manufacturing and transport, while legislative and corporate activities are driving sectors, finally agriculture and construction are independent sectors.
\end{abstract}

Key words: Key sectors, social accounting matrix, multiplier effect. 


\section{INTRODUCCIÓN}

Una de las principales y más útiles aplicaciones de los modelos de equilibrio general aplicado se encuentra en el ámbito de las políticas públicas. La utilización de este tipo de modelos permite analizar el impacto que la imposición de nuevas políticas tendrá sobre los diferentes agentes sociales. Lo anterior disminuye el costo y los riesgos que conlleva la aplicación de políticas públicas, lo cual en países con recursos limitados supone un gran avance.

El estudio con matrices de contabilidad social se ha desarrollado en las últimas décadas y, con ello, ha tomado una mayor fuerza al reconocer las bondades que supone el estudio estructural, así como trabajos más especializados que contemplan todo el ciclo económico de una entidad o país.

Para México se tienen estudios de gran aportación que parten de la elaboración de matrices de contabilidad social. Uno de los primeros trabajos para el país que ocupa una matriz de contabilidad social es el de Kehoe et al. (1984) en donde se analiza el impacto de la reforma fiscal del año 1980 y donde la matriz es utilizada para la elaboración del modelo de equilibrio general.

Otro trabajo es el de Casares et al. (2017), quienes elaboran la matriz de contabilidad social del año 2003 y pretenden resaltar la utilidad de las matrices en el estudio estructural o multisectorial, con un grado de desagregación mayor.

Nuñez y Polo (2010) hacen un análisis estructural de la economía mexicana que tiene como base la matriz de contabilidad social del año 1996, en él se pretende cimentar la elaboración de matrices de contabilidad social y con ello instrumentar los modelos de equilibrio general aplicado.

Por su parte, Albornoz y Ortiz (2016) estiman los efectos multisectoriales por la reducción de las remesas internacionales en el año 2002, con base en una matriz de contabilidad social de 1996 actualizada bajo el método de entropía al año 2002.

Otro estudio es el de Aguayo et al. (2009), que construye una matriz de contabilidad social para el año 2004 con la desagregación de hogares y analiza la generación y redistribución de la renta en México. 
A pesar de los esfuerzos de los investigadores por generar periódicamente la matriz de contabilidad social en México, aún no se genera y publica de manera oficial, contando únicamente con la matriz de insumo producto a partir de la cual se construye la de contabilidad social.

Existen, sin embargo, matrices de contabilidad social que se han construido en el área académica, entre las que destaca la de Beltrán et al. (2016) para el año 2008 como la más reciente, precedida por la macro matriz de contabilidad social de México para el año 2003 de Núñez (2014), así como la de Barboza et al. (2012) que realizan la matriz de contabilidad social para México del año 2004.

En trabajos más especializados para el país se encuentra el trabajo de Yúnez y González (2008), quienes generan una matriz de contabilidad social de diez comunidades rurales con características similares de pobreza.

Para el estudio regional se encuentra el trabajo de Chapa y Rangel (2010) que a través de la elaboración de una matriz para el estado de Nuevo León para el año 2004, analizan la estructura productiva y de ingreso gasto del estado.

La elaboración de una matriz para pueblos por Núñez y Mendoza (2008) se realiza desde el instrumento de medición, aplicación de la encuesta, procesamiento de la misma y el análisis estructural para el municipio de Los Lirios en Arteaga, Coahuila. Así como la matriz de contabilidad para pueblos, elaborada para el municipio de Aquismón, San Luis Potosí, México, de Cardona y Núñez (2015).

Para la elaboración de este trabajo se construye la matriz de contabilidad social para México del año 2012, en lo sucesivo MCSMEX12, utilizando la última matriz de insumo producto (MIP) publicada por el Instituto Nacional de Geografía y Estadística (INEGI) para el año 2012. De tal forma que se actualiza el año de revisión de la estructura económica de México al 2012 y se comparan los resultados para observar la congruencia entre la técnica de multiplicadores generalizados y los indicadores de absorción y arrastre.

El objetivo de este artículo es identificar los sectores clave de la economía mexicana para el año 2012, a través de la construcción, análisis y presentación de resultados de la MCSMEX12, mismos que 
puedan ser considerados para potencializar el desarrollo económico del país.

La hipótesis es entonces que, a través de la utilización de modelos de equilibrio general aplicado, específicamente un modelo lineal, serán identificados los sectores productivos clave de la economía mexicana, en donde la manufactura ya no será el motor de crecimiento económico que por décadas fue para el país.

La sección dos de este trabajo muestra un panorama económico de México, en donde se aprecia que del año 2006 al 2015 las dos actividades económicas con mayor participación en el Producto Interno Bruto (PIB) son la industria manufacturera y el comercio; la primera presenta una tendencia a la baja hacia el año 2015 y el segundo muestra un constante incremento desde 2006.

En la tercera parte se detalla la construcción de la MCSMEX12, que parte de la MIP doméstica para el año 2012, se transfiere a un formato de matriz de contabilidad social que después es desglosado con el apoyo de las cuentas de bienes y servicios, así como de sectores institucionales.

La cuarta sección contiene el análisis estructural que muestra la aplicación del modelo de multiplicadores generalizados y los índices de arrastre y dispersión. Por último, se presentan las conclusiones.

\section{PANORAMA ECONÓMICO DE MÉXICO}

Al realizar una comparación entre el ingreso per cápita, la inflación y el PIB del año 2010 con 2011, esta no es proporcional al crecimiento de la población, lo que el Fondo Monetario Internacional (FMI) denota como crecimiento insuficiente. Este hecho se ha replicado en las últimas décadas provocando los efectos de la falta de crecimiento en México e identificados como: baja producción de bienes y servicios, menor ahorro e inversión, bajo ingreso per cápita que, a su vez, genera un bajo nivel de vida, así como una balanza comercial desfavorable. 
La economía mexicana depende en gran medida de las exportaciones que realiza a Estados Unidos de América, su principal socio comercial, el cual adquiere $85 \%$ de las exportaciones del país.

Al realizar un primer análisis por sector en el periodo $2006-2015^{2}$ se detecta que es el sector manufacturero el que representa una mayor proporción de participación en el PIB con 16.6 por ciento. Por otra parte, el sector comercio representa $14.8 \%$, seguido por los servicios inmobiliarios con una participación de $11.9 \%$, todas en promedio anual como se puede observar en el cuadro 1.

\section{Cuadro 1}

Participación en el PIB por sector productivo de México 2006-2015

\begin{tabular}{|l|c|c|c|c|c|c|c|c|c|c|}
\hline \multicolumn{1}{|c|}{ Sector productivo } & 2006 & 2007 & 2008 & 2009 & 2010 & 2011 & 2012 & 2013 & 2014 & 2015 \\
\hline Impuestos a los productos netos & 2.57 & 2.57 & 2.58 & 2.58 & 2.58 & 2.58 & 2.58 & 2.58 & 2.65 & 2.72 \\
\hline $\begin{array}{l}\text { Agricultura, cría y explotación de } \\
\text { animales, aprovechamiento forestal, } \\
\text { pesca y caza }\end{array}$ & 3.19 & 3.23 & 3.21 & 3.24 & 3.18 & 2.87 & 2.99 & 3.03 & 3.06 & 3.01 \\
\hline Minería & 9.49 & 9.06 & 8.60 & 8.67 & 8.31 & 7.97 & 7.73 & 7.61 & 7.34 & 6.83 \\
\hline $\begin{array}{l}\text { Generación, transmisión y } \\
\text { distribución de energía eléctrica, } \\
\text { suministro de agua y de gas por } \\
\text { ductos al consumidor final }\end{array}$ & 2.00 & 2.06 & 2.06 & 2.19 & 2.18 & 2.24 & 2.20 & 2.18 & 2.31 & 2.30 \\
\hline Construcción & 8.10 & 8.21 & 8.41 & 8.29 & 7.94 & 7.95 & 7.83 & 7.35 & 7.34 & 7.33 \\
\hline Industrias manufactureras & $\mathbf{1 7 . 3 2}$ & $\mathbf{1 6 . 9 4}$ & $\mathbf{1 6 . 5 4}$ & $\mathbf{1 5 . 9 1}$ & $\mathbf{1 6 . 4 2}$ & $\mathbf{1 6 . 5 3}$ & $\mathbf{1 6 . 5 4}$ & $\mathbf{1 6 . 5 1}$ & $\mathbf{1 6 . 8 1}$ & $\mathbf{1 6 . 8 0}$ \\
\hline Comercio & $\mathbf{1 4 . 6 3}$ & $\mathbf{1 4 . 7 5}$ & $\mathbf{1 4 . 5 7}$ & $\mathbf{1 3 . 3 9}$ & $\mathbf{1 4 . 2 4}$ & $\mathbf{1 5 . 0 4}$ & $\mathbf{1 5 . 1 4}$ & $\mathbf{1 5 . 2 6}$ & $\mathbf{1 5 . 4 0}$ & $\mathbf{1 5 . 7 1}$ \\
\hline $\begin{array}{l}\text { Transportes, correos y } \\
\text { almacenamiento }\end{array}$ & $\mathbf{5 . 7 9}$ & 5.80 & 5.72 & 5.57 & 5.70 & 5.71 & 5.71 & 5.77 & 5.82 & 5.92 \\
\hline Información en medios masivos & 2.17 & 2.53 & 2.65 & 3.01 & 2.89 & 2.91 & 3.25 & 3.36 & 3.30 & 3.46 \\
\hline Servicios financieros y de seguros & 2.42 & 2.65 & 3.19 & 3.46 & 3.98 & 4.10 & 4.24 & 4.62 & 4.48 & 4.56 \\
\hline
\end{tabular}

2 Los datos de la Cuenta de Bienes y Servicios del Sistema de Cuentas Nacionales para 20032005 están incompletos. 


\begin{tabular}{|l|l|l|l|l|l|l|l|l|l|l|}
\hline $\begin{array}{l}\text { Servicios inmobiliarios y de alquiler } \\
\text { de bienes muebles e intangibles }\end{array}$ & 11.59 & 11.60 & 11.82 & 12.54 & 12.25 & 12.13 & 11.95 & 11.90 & 11.88 & 11.87 \\
\hline $\begin{array}{l}\text { Servicios profesionales, científicos y } \\
\text { técnicos }\end{array}$ & 2.31 & 2.32 & 2.36 & 2.35 & 2.23 & 2.26 & 2.19 & 2.19 & 2.18 & 2.21 \\
\hline Corporativos & 0.58 & 0.57 & 0.61 & 0.58 & 0.58 & 0.58 & 0.61 & 0.59 & 0.62 & 0.62 \\
\hline $\begin{array}{l}\text { Servicios de apoyo a los negocios y } \\
\text { manejo de desechos y servicios de } \\
\text { remediación }\end{array}$ & 3.23 & 3.23 & 3.25 & 3.18 & 3.04 & 3.10 & 3.11 & 3.20 & 3.12 & 3.08 \\
\hline Servicios educativos & 3.92 & 3.86 & 3.85 & 4.05 & 3.86 & 3.77 & 3.71 & 3.68 & 3.60 & 3.51 \\
\hline $\begin{array}{l}\text { Servicios de salud y de asistencia } \\
\text { social }\end{array}$ & 2.06 & 2.04 & 2.04 & 2.19 & 2.08 & 2.04 & 2.00 & 1.99 & 1.93 & 1.84 \\
\hline $\begin{array}{l}\text { Servicios de esparcimiento culturales } \\
\text { y deportivos, y otros servicios } \\
\text { recreativos }\end{array}$ & 0.47 & 0.47 & 0.47 & 0.47 & 0.47 & 0.45 & 0.44 & 0.45 & 0.43 & 0.44 \\
\hline $\begin{array}{l}\text { Servicios de alojamiento temporal } \\
\text { y de preparación de alimentos y } \\
\text { bebidas }\end{array}$ & 2.30 & 2.30 & 2.27 & 2.15 & 2.08 & 2.04 & 2.06 & 2.07 & 2.08 & 2.15 \\
\hline $\begin{array}{l}\text { Otros servicios excepto actividades } \\
\text { gubernamentales }\end{array}$ & 2.08 & 2.09 & 2.09 & 2.18 & 2.09 & 2.05 & 2.03 & 2.05 & 2.04 & 2.04 \\
\hline $\begin{array}{l}\text { Actividades legislativas, } \\
\text { gubernamentales, de impartición } \\
\text { de justicia y de organismos } \\
\text { internacionales y extraterritoriales }\end{array}$ & 3.79 & 3.71 & 3.74 & 4.00 & 3.90 & 3.70 & 3.69 & 3.62 & 3.61 & 3.61 \\
\hline
\end{tabular}

Fuente: Elaboración propia con datos de la Cuenta de Bienes y Servicios del Sistema de Cuentas Nacionales, INEGI, 2017.

Los tres sectores con mayor participación en el PIB son la industria manufacturera, el comercio y servicios inmobiliarios, en promedio anual. Si bien la manufactura es parte de las actividades secundarias, el comercio y los servicios inmobiliarios pertenecen al tercer sector. Por lo que, a prio$r i$, nos permite mencionar que el país concentra su actividad económica en el segundo y tercer sector.

Se observa que la industria manufacturera presenta una disminución en la aportación del PIB del año 2006 al 2015 de 3.18 puntos 
porcentuales de participación, mientras que el comercio tiene un aumento en su contribución de 6.87 puntos porcentuales para el año 2015 respecto al 2006.

Para el año 2012 la participación de los tres grupos de actividad económica de México presenta la distribución que puede observarse en la gráfica 1 .

\section{Gráfica 1}

Distribución de participación de los sectores en el año 2012

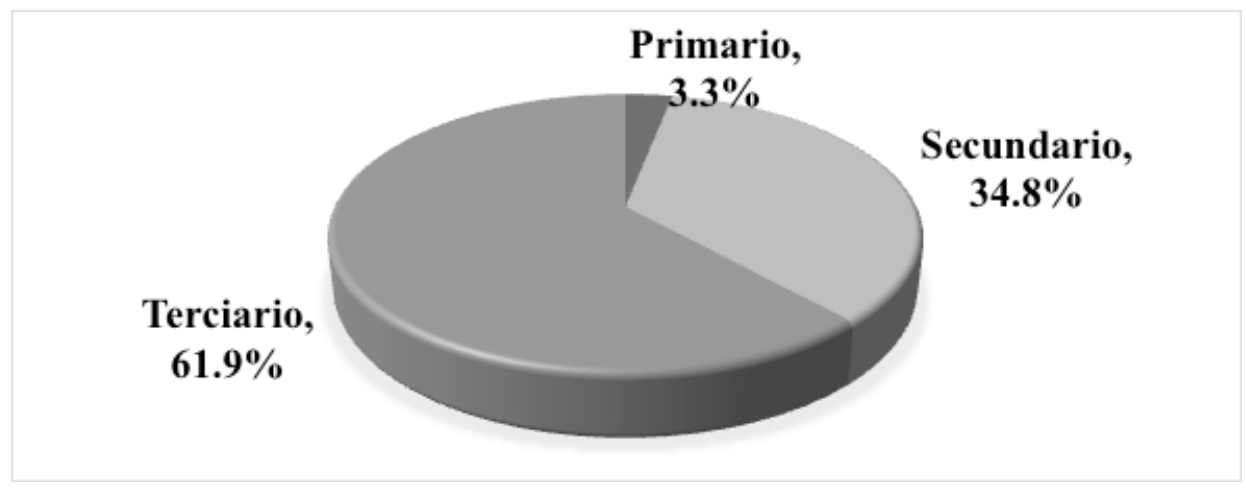

Fuente: Elaboración propia con datos del INEGI (2017).

Se aprecia con claridad que la mayor aportación al PIB es por el sector terciario con $61.9 \%$, seguido del sector secundario con $34.8 \%$ en donde se encuentran registradas las manufacturas y finalmente el sector primario con 3.3 por ciento. Lo cual es congruente con el cuadro 1 que muestra los 19 sectores económicos del país y su participación en el PIB por sector. La participación de los estados en cada actividad económica es representativa de su fuente de crecimiento, obsérvese el cuadro 2 . 


\section{Cuadro 2}

Participación de los estados en las actividades económicas de México, 2012 (precios corrientes) $^{3}$

\begin{tabular}{|c|c|c|c|}
\hline Estado & Primarias \% & Secundarias \% & Terciarias $\%$ \\
\hline Aguascalientes & $1.47 \%$ & 1.26 & 0.97 \\
\hline Baja California & 2.52 & 3.28 & 2.83 \\
\hline Baja California Sur & 0.74 & 0.60 & 0.84 \\
\hline Campeche & 0.84 & 13.15 & 0.76 \\
\hline Coahuila de Zaragoza & 2.55 & 5.46 & 2.52 \\
\hline Colima & 0.82 & 0.46 & 0.62 \\
\hline Chiapas & 4.47 & 1.62 & 1.82 \\
\hline Chihuahua & 5.44 & 3.47 & 2.65 \\
\hline Ciudad de México & 0.20 & 5.59 & 23.86 \\
\hline Durango & 3.51 & 1.06 & 1.11 \\
\hline Guanajuato & 4.46 & 3.66 & 3.66 \\
\hline Guerrero & 2.20 & 0.74 & 1.71 \\
\hline Hidalgo & 2.13 & 1.65 & 1.40 \\
\hline Jalisco & 11.01 & 5.54 & 6.53 \\
\hline México & 3.94 & 6.81 & 9.66 \\
\hline Michoacán de Ocampo & 7.72 & 1.31 & 2.52 \\
\hline Morelos & 1.00 & 1.02 & 1.18 \\
\hline Nayarit & 1.72 & 0.39 & 0.73 \\
\hline Nuevo León & 1.27 & 7.77 & 7.24 \\
\hline Oaxaca & 2.83 & 1.45 & 1.66 \\
\hline Puebla & 4.33 & 3.46 & 3.25 \\
\hline Querétaro & 1.52 & 2.22 & 1.95 \\
\hline Quintana Roo & 0.37 & 0.44 & 1.98 \\
\hline San Luis Potosí & 1.99 & 2.18 & 1.80 \\
\hline Sinaloa & 7.09 & 1.28 & 2.33 \\
\hline Sonora & 6.05 & 4.10 & 2.52 \\
\hline Tabasco & 1.46 & 8.05 & 1.63 \\
\hline Tamaulipas & 3.53 & 3.49 & 2.72 \\
\hline Tlaxcala & 0.72 & 0.60 & 0.55 \\
\hline Veracruz de Ignacio de la Llave & 8.11 & 5.52 & 4.66 \\
\hline Yucatán & 1.64 & 1.07 & 1.51 \\
\hline Zacatecas & 2.36 & 1.31 & 0.80 \\
\hline
\end{tabular}

Fuente: Elaboración propia con datos del INEGI, 2017.

3 El total de cada columna es igual a 100. 
En las actividades primarias es el estado de Jalisco el que presenta una mayor participación con un total de $11.01 \%$ y el estado con menor participación en esta actividad es la Ciudad de México con 0.20 por ciento.

En las actividades secundarias el primer lugar de participación en el PIB en México la ocupa el estado de Campeche con 13.15\%, seguido por Tabasco con $8.05 \%$ y Nuevo León con $7.77 \%$, el estado de México con $6.81 \%$ en la cuarta posición, finalmente el estado con menor aportación es Nayarit con 0.37 por ciento.

La Ciudad de México es el estado con mayor participación en el sector terciario con $23.86 \%$, seguido del estado de México con $9.66 \%$, Nuevo León con $7.24 \%$, Jalisco con $6.53 \%$ y con la menor participación están dada los estados de Tlaxcala y Colima con el $0.55 \%$ y $0.62 \%$ respectivamente. Es importante mencionar que en este tercer sector se encuentran registrados los servicios de esparcimiento, hospedaje, alimentos, financieros, ocio, además de comercio.

De acuerdo con los datos presentados anteriormente de INEGI (2017) es posible observar que los estados que mayor aportación al PIB nacional ofrecen son la Ciudad de México con una participación promedio en 2012 de $16.72 \%$, seguido del estado de México con 8.48\%, Nuevo León con $7.23 \%$, Jalisco con $6.33 \%$ y Campeche con $5.08 \%$, lo que nos refiere a la posibilidad de estudiar dichos estados en lo particular en una segunda etapa de investigación, ya que cada uno tiene inclinación por un sector, a reserva del estado de Nuevo León que aporta alrededor de 7 puntos porcentuales al PIB nacional por el sector secundario y terciario.

\section{ELABORACIÓN DE LA MATRIZ DE CONTABILIDAD SOCIAL PARA MÉXICO 2012}

Los primeros trabajos de cuentas sociales, en donde se define a la contabilidad social como "la actividad de concepción y construcción de un sistema de cuentas que comprende todas las ramificaciones de la economía, hasta donde sea susceptible la medición incluyendo de esa manera todas las subdivisiones de las cuentas necesarias" es la aportación del padre de la contabilidad social, Stone (1969:79). 
Stone refiere que uno de los principales problemas en la contabilidad social es la conciliación de las subcuentas a las agregadas, ya que para un sistema de cuentas tradicional la clasificación de gasto por parte del consumidor se refiere a una lista de compras, mientras que en un modelo input-output se basa en la clasificación de la industria.

Una vez obtenidas las aportaciones de Stone, Pyatt y Thorbecke (1976) formalizan la matriz de contabilidad social (MCS) al realizar la demostración de cómo era posible utilizarla como cuadro de trabajo para formular propuestas de política y de planeación.

Pyatt (1991) publicó un artículo en el que hace un llamado a la Organización de las Naciones Unidas (ONU) para hacer una revisión del sistema de cuentas nacionales de 1968 y, con ello, se permitiera dar mayor énfasis a conceptos esenciales, de tal modo que cada país tenga la oportunidad de elaborar sus propias MCSs, además de sugerir que los modelos de equilibrio general computable reemplacen la metodología input-output como herramienta central del sistema.

Lamentablemente, aún no se ha logrado que los modelos de equilibrio general computable sea la herramienta principal de los gobiernos al momento de realizar la política pública. Sin embargo, lo que ya es parte del avance es el sistema de cuentas nacionales que, para el año 2003, es el primer intento por unificar la estructura de los tres principales sectores y en donde México fue el país piloto en la aplicación de esta metodología de acuerdo con el INEGI (2003). Para el año 2008, en la revisión del sistema de cuentas nacionales de la ONU (2008), ya se cuenta con un título general de entradas y salidas, así como otras matrices basadas en análisis.

En la actualidad para numerosos países en el mundo se construye de forma sistemática la MCS para cada año, esto a través del Global Trade Analysis Project (GTAP), en donde los usuarios interesados, bajo los lineamientos de dicha institución, generan las matrices de contabilidad social, una vez realizadas pasan por un filtro de la propia institución para ser publicadas y estar a disposición del resto de los usuarios. ${ }^{4}$ Este no es el caso de México y, por lo tanto, aún no se tiene establecido un solo formato

4 Para mayor detalle de las SAM's de GTAP consultar: https://www.gtap.agecon.purdue.edu/ databases/v9/default.asp 
para su elaboración, es por dicha razón que al elaborarla debe tenerse el mayor rigor técnico posible de acuerdo con la literatura antes mencionada.

El desarrollo de esta investigación requiere de la elaboración de una matriz de contabilidad social para el año 2012, ya que no existe ninguna publicada hasta el momento. Para la elaboración de la MCSMEX12 se inicia con la matriz simétrica domestica insumo-producto; producto por producto, por sector de la actividad para la economía total, en millones de pesos del año 2012.

Para las desagregaciones se utilizan datos de las cuentas de bienes y servicios y la cuenta de sectores institucionales. La MCSMEX12 se compone de ocho grandes grupos, de los cuales el primero contiene 19 cuentas que comprende los sectores productivos, el segundo grupo corresponde a trabajo, el cual se conforma de tres cuentas, enseguida se encuentra el grupo capital con una cuenta, le sigue el cuarto grupo llamado empresas que se compone por dos cuentas; enseguida tenemos el grupo de hogares, que en esta MCS es el global de los hogares, ya que pueden ser desagregados hasta en diez déciles, el sexto grupo es gobierno con cinco cuentas, el siguiente es ahorro-inversión (A-I), también conocida como capital, finalmente el resto del mundo, con una sola cuenta. Para observar en detalle véase el cuadro 3.

Como ya se ha mencionado, para la elaboración de la MCSMEX12 se parte de la MIP doméstica producto por producto, por sector de la economía para el año 2012, con ella se reordenan las cuentas con la finalidad de poder transferirnos de la MIP a la MCS de una forma más ordenada y así evitar la pérdida de datos.

Se toma el total de usos de origen nacional, importaciones totales, impuestos sobre bienes y servicios netos de subsidios, sueldos y salarios que incluyen contribuciones sociales efectivas a la seguridad social, otras prestaciones sociales, total de remuneraciones de asalariados, impuestos netos de subsidios sobre la producción, excedente bruto de operación, valor agregado bruto a precios básicos, producción de la economía total a precios básicos y producto interno bruto de la economía total.

De estas cuentas se conserva el total del consumo intermedio, consumo privado, consumo de gobierno, formación bruta de capital fijo, valoración de existencias, exportaciones de economía interna y la demanda final, ver cuadro 4. 


\section{Cuadro 3}

\section{Grupos y cuentas de la MCSMEX12}

\begin{tabular}{|c|c|c|}
\hline Grupo & Cuenta & Descripción \\
\hline \multirow{19}{*}{$\begin{array}{l}\text { Sectores } \\
\text { productivos }\end{array}$} & 1 & Agricultura, cría y explotación de animales, aprovechamiento forestal, pesca y caza \\
\hline & 2 & Minería \\
\hline & 3 & $\begin{array}{l}\text { Generación, transmisión y distribución de energía eléctrica, suministro de agua y de gas } \\
\text { por ductos al consumidor final }\end{array}$ \\
\hline & 4 & Construcción \\
\hline & 5 & Industrias manufactureras \\
\hline & 6 & Comercio \\
\hline & 7 & Transportes, correos y almacenamiento \\
\hline & 8 & Información en medios masivos \\
\hline & 9 & Servicios financieros y de seguros \\
\hline & 10 & Servicios inmobiliarios y de alquiler de bienes muebles e intangibles \\
\hline & 11 & Servicios profesionales, científicos y técnicos \\
\hline & 12 & Corporativos \\
\hline & 13 & Servicios de apoyo a los negocios y manejo de desechos y servicios de remediación \\
\hline & 14 & Servicios educativos \\
\hline & 15 & Servicios de salud y de asistencia social \\
\hline & 16 & Servicios de esparcimiento culturales y deportivos, y otros servicios recreativos \\
\hline & 17 & Servicios de alojamiento temporal y de preparación de alimentos y bebidas \\
\hline & 18 & Otros servicios excepto actividades gubernamentales \\
\hline & 19 & $\begin{array}{l}\text { Actividades legislativas, gubernamentales, de impartición de justicia y de organismos } \\
\text { internacionales y extraterritoriales }\end{array}$ \\
\hline \multirow{3}{*}{ Trabajo } & 20 & Trabajo \\
\hline & 21 & Contribuciones sociales efectivas a la seguridad social \\
\hline & 22 & Otras prestaciones sociales \\
\hline Capital & 23 & Capital \\
\hline \multirow{2}{*}{ Empresas } & 24 & Sociedades \\
\hline & 25 & Consumo privado \\
\hline Hogares & 26 & Hogares \\
\hline \multirow{5}{*}{ Gobierno } & 27 & Gobierno \\
\hline & 28 & Impuesto sobre la renta \\
\hline & 29 & Impuestos sobre bienes y servicios netos de subsidios \\
\hline & 30 & impuestos netos de subsidios sobre la producción \\
\hline & 31 & Otros impuestos a la producción (OIP) \\
\hline Ahorro-Inversión & 32 & Cuenta de capital (ahorro-inversión) \\
\hline Resto del mundo & 33 & Resto del mundo \\
\hline
\end{tabular}

Fuente: Elaboración propia con datos del INEGI (2012). 


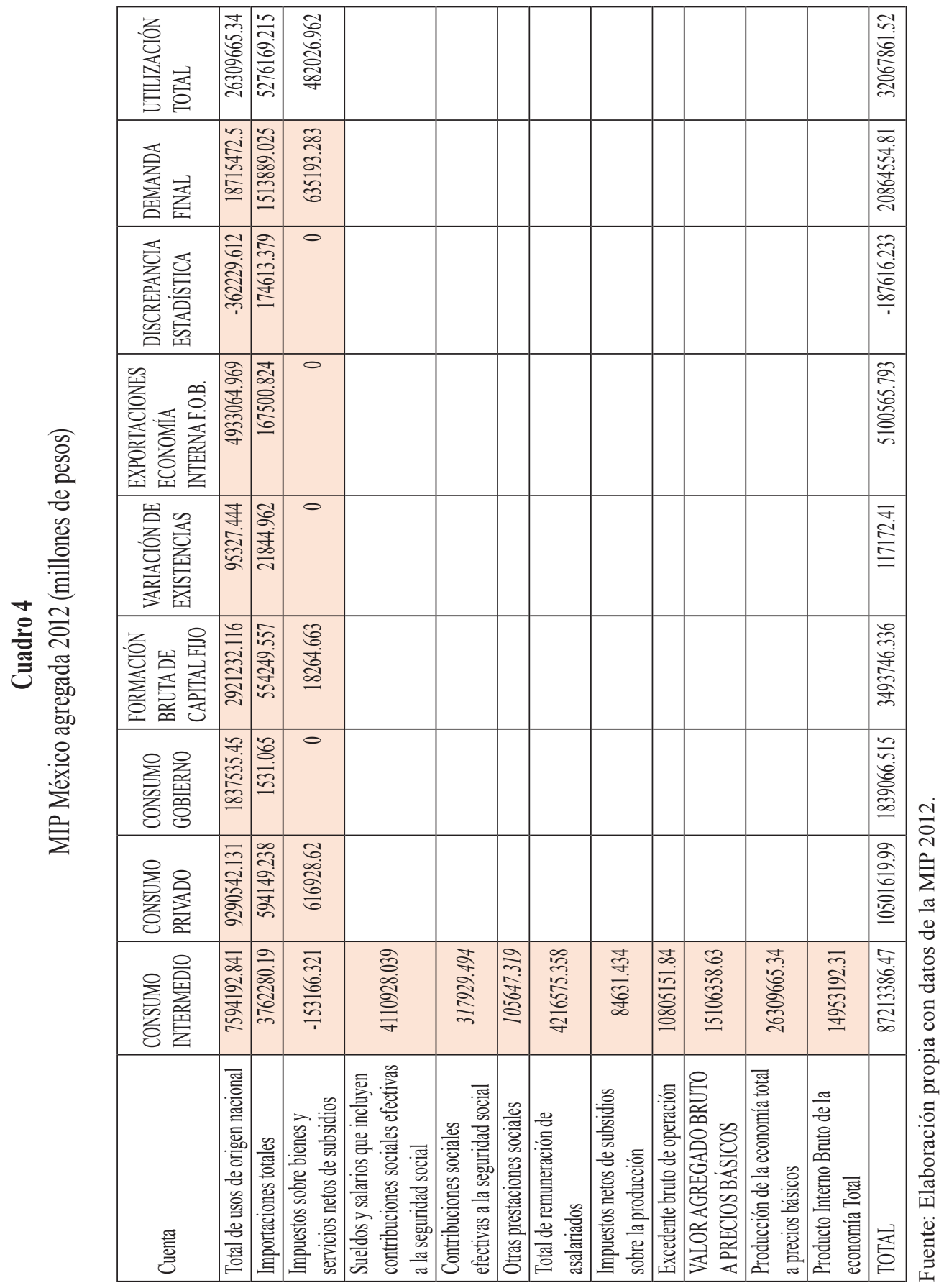

Revista de Economía - Vol. XXXV - Núm. 90 
El siguiente paso ha sido la transferencia de la MIP a la MCS, como es posible observar en el cuadro 4 la forma de L invertida se mantiene, característica de la MIP que sólo recoge las transferencias de producción.

Posteriormente, es necesario colocar la MIP en formato de MCS, donde los hogares reciben $\$ 4,534,504.85$, de los cuales $\$ 4,110,928.04$ son por concepto de trabajo y $\$ 423,576.81$ por las contribuciones sociales, estos a su vez transfieren al gobierno $\$ 616,928.62$ por concepto de impuestos sobre bienes y servicios, además transfieren a las actividades y resto del mundo un monto de $\$ 9,884,691.37$.

Las actividades reciben de los hogares $\$ 9,290,542.13$, las transferencias que reciben del gobierno son $\$ 1,837,535.45$, por parte de la inversión reciben $\$ 3,016,559.56$, y entre ellas mismas el flujo de efectivo es de $\$ 7,594,192.84$ y las importaciones realizadas, reflejadas en la cuenta del resto del mundo, tienen un valor de $\$ 4,933,064$.97. A la salida de su flujo monetario $-\$ 153,166.32$, es por concepto de impuestos de bienes y servicios netos, $\$ 84,631.43$ corresponde a los impuestos imputados sobre la producción, al capital transfieren $\$ 10,805,151.84$ y al trabajo $\$ 4,110,928.04$, mismos que vemos reflejados en las transferencias a hogares por concepto de trabajo.

Las sociedades reciben directamente del capital $\$ 10,805,151.84$. El gobierno tiene ingresos generados por los impuestos sobre bienes y servicios y los impuestos netos de subsidios sobre la producción por un total de $\$ 566,658.40$ y tiene erogaciones, además de los hogares, con las actividades por $\$ 1,837,535.45$ y el resto del mundo $\$ 1,531.07$.

El resto del mundo reporta ingresos por parte del gobierno, la inversión es por $\$ 576,094.52$ y el mismo resto del mundo por $\$ 167,500.82$, que más tarde absorberá la diferencia estadística quedando cuadrada las manufacturas al momento de desagregar. El cuadro 5 muestra la transferencia de la MIP a la MCS. 


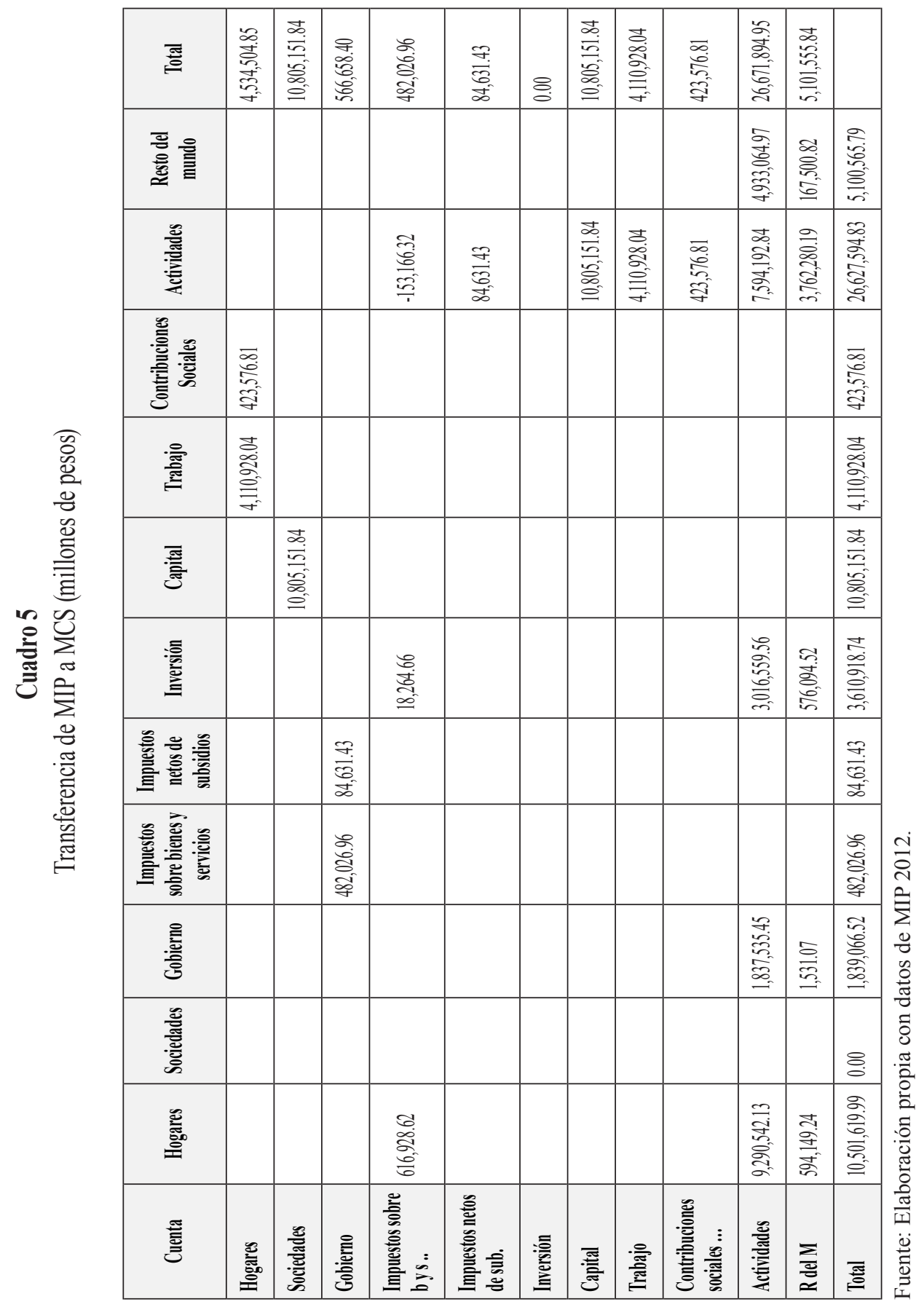

Revista de Economía - Vol. XXXV - Núm. 90 
Una vez que se tiene el formato agregado y aún no cuadrado de la MCS se inicia con la desagregación de las cuentas, la integración de las subcuentas que obtenemos de la cuenta de sectores institucionales 2012 (CSI) va a permitir cerrar las triangulaciones de los flujos monetarios de la economía mexicana y con ello poder pasar al balanceo de la MCSMEX12.

Un primer paso es desagregar las actividades, las cuales pasan directamente de la MIP a MCSMEX12, se agrega el consumo privado y el gobierno, retomándolas de la MIP.

La cuenta de ahorro e inversión es actualizada por proporción a los datos del año 2008 ya que en 2012 no se presentan desagregados en la CSI. Enseguida tenemos el trabajo, las contribuciones sociales y otras contribuciones, de igual forma se toman los desagregados de la MIP 2012.

Se desagrega por sector los impuestos sobre bienes y servicios netos de subsidios, los impuestos netos de subsidio sobre la producción y otros impuestos a la producción, estos últimos son un ajuste al excedente bruto de operación (EBO).

Enseguida se desagregan las importaciones totales por subsector, lo que corresponde a resto del mundo (RdM).

De acuerdo con la CSI los hogares tienen ingresos por concepto de trabajo por un monto de $\$ 4,408,958.03$, por las contribuciones sociales y otras contribuciones un total de $\$ 560,326.13$.

El capital y las sociedades tienen un intercambio por $\$ 8,737,034.57$, donde las empresas aportan a los hogares un ingreso de $\$ 6,253,723.68$.

Los impuestos sobre la renta, productos y producción son obtenidos de la CSI, corroborados y desagregados con datos de la MIP.

De las erogaciones del gobierno, respecto a A-I tomado de la CSI tenemos un monto por $\$ 142,585.97$.

Finalmente, el RdM se alimenta tanto de las importaciones como las exportaciones, la diferencia estadística y de la CSI, quedando respaldada por los cruces de las cuentas anteriores.

Es importante mencionar que al colocar los montos entre la MIP 2012, alimentada por la CSI del mismo año, la matriz no queda totalmente cuadrada, por lo que es necesario proceder al balanceo. 
Actualmente es posible realizar las calibraciones con software especializado como lo es el SimSip-Sam, es una herramienta libre que consta de una caratula de Excel soportada en Matlab dedicada al análisis de matrices de contabilidad social y que permite desde el balanceo de la matriz hasta la obtención de índices de absorción, indicadores de empleo, entre otros.

Es un método muy flexible que incorpora restricciones adicionales al problema de la estimación. Para la MCSMEX12 se optó por el método de entropía, donde el PIB es el principal medio de control, se colocó un nivel de tolerancia de 0.00001 y un error estándar de 0.05. A diferencia del método de balanceo RAS, la entropía no requiere de una matriz previa con la que sea posible realizar una actualización.

El método RAS fue diseñado por Stone (1961), motivo por el cual este método lleva sus iniciales, en la actualidad es un método vigente utilizado incluso por entidades de estadística como lo es el INEGI en México, sin embargo, a la evolución de la ciencia económica se une el desarrollo de métodos de calibración, como lo es la entropía, que si bien puede ser o no mejor, ${ }^{5}$ nos permite la calibración sin una matriz previa, motivo por el que ha sido aplicado en este trabajo.

Una vez aplicado el método de entropía la MCSMEX12 está en condiciones para ser analizada, aplicar el modelo de multiplicadores generalizados y obtener los sectores clave de la economía mexicana para el año 2012. La MCSMEX12 se puede observar en el cuadro 6.

5 Para una amplia exposición de la congruencia de los resultados entre estos dos métodos consulte Parra y Pino (2012). 


\section{Cuadro 6}

MCSMEX12 (millones de pesos)

\begin{tabular}{|c|c|c|c|c|c|c|c|c|c|}
\hline SUBSECT0R & 1 & 2 & 3 & 4 & 5 & 6 & 7 & 8 & 9 \\
\hline 1 & $78,301.85$ & 0.00 & 24.71 & 596.54 & $346,541.09$ & 0.75 & 0.00 & 0.00 & 0.00 \\
\hline 2 & $1,171.88$ & $40,768.73$ & $8,829.19$ & $34,174.74$ & $827,888.94$ & 54.05 & 217.35 & 0.00 & 0.00 \\
\hline 3 & $12,106.97$ & $9,122.78$ & $3,422.52$ & $7,397.45$ & $80,457.80$ & $50,383.58$ & $9,739.38$ & $6,055.84$ & $4,696.40$ \\
\hline 4 & 2.04 & $5,254.93$ & $1,564.77$ & $171,334.77$ & $3,161.63$ & $4,702.92$ & $3,187.15$ & 4.08 & 0.00 \\
\hline 5 & $145,651.65$ & $87,336.75$ & $160,987.17$ & $483,189.93$ & $1,261,337.34$ & $209,270.54$ & $463,391.06$ & $32,174.94$ & 22,387.91 \\
\hline 6 & $29,962.46$ & $20,863.55$ & $29,485.28$ & $100,998.31$ & $418,591.67$ & $41,397.82$ & $53,255.86$ & $17,098.14$ & $6,669.49$ \\
\hline 7 & $6,245.45$ & $5,465.46$ & $9,675.82$ & $21,719.88$ & $115,855.52$ & $26,713.47$ & $41,786.64$ & $9,282.39$ & $13,954.29$ \\
\hline 8 & 128.78 & $1,274.07$ & 918.65 & $10,454.48$ & $9,672.38$ & $15,721.20$ & $7,098.00$ & $25,708.08$ & $64,324.00$ \\
\hline 9 & $4,187.52$ & $7,655.78$ & $1,233.70$ & $38,631.85$ & $27,215.96$ & $16,569.40$ & $10,883.47$ & $13,650.47$ & $79,657.03$ \\
\hline 10 & $2,663.65$ & $6,279.61$ & 521.67 & $11,992.72$ & $37,349.74$ & $83,314.54$ & $16,478.03$ & $14,658.51$ & $16,120.05$ \\
\hline 11 & 939.38 & $15,838.87$ & $4,824.90$ & $22,117.62$ & $61,278.14$ & $37,218.31$ & $34,311.64$ & $18,012.29$ & $35,549.14$ \\
\hline 12 & 61.27 & $12,038.79$ & 947.74 & 137.14 & $14,421.22$ & $15,416.98$ & $9,440.17$ & $8,819.37$ & $22,918.71$ \\
\hline 13 & 773.39 & $10,959.10$ & $1,937.40$ & $25,913.08$ & $128,005.86$ & $158,498.85$ & $27,196.45$ & $25,824.99$ & $28,156.13$ \\
\hline 14 & 2.01 & 0.42 & 231.06 & 5.01 & 170.76 & 131.92 & $1,661.06$ & 68.89 & $1,244.96$ \\
\hline 15 & 0.00 & 0.00 & 0.00 & 0.00 & 0.00 & 0.00 & 0.00 & 0.00 & 0.00 \\
\hline 16 & 0.00 & 0.00 & 0.00 & 0.23 & 0.00 & 3.28 & 10.37 & 977.36 & 39.92 \\
\hline 17 & 217.99 & $1,891.56$ & 832.04 & $4,855.60$ & $8,094.40$ & $6,633.13$ & $6,840.62$ & $2,603.46$ & $3,733.45$ \\
\hline 18 & 718.64 & $1,239.24$ & 723.03 & $8,765.96$ & $11,181.00$ & 10,501.11 & $10,340.13$ & $1,007.37$ & $8,239.58$ \\
\hline 19 & 0.00 & 0.00 & 0.00 & 0.01 & 0.43 & 906.84 & 0.00 & 0.00 & 0.00 \\
\hline 20 & $88,455.28$ & $63,324.77$ & $51,604.32$ & $518,396.38$ & $449,550.84$ & $452,458.86$ & $307,573.13$ & $80,787.93$ & $131,796.65$ \\
\hline 21 & 254.94 & $11,111.03$ & $4,063.06$ & $102,773.40$ & 145.48 & 0.00 & $2,741.09$ & $8,250.70$ & 0.00 \\
\hline 22 & 0.00 & 994.53 & 496.44 & $55,723.56$ & $13,177.07$ & $6,873.22$ & $4,578.59$ & 882.19 & $9,066.01$ \\
\hline 23 & $353,113.41$ & $867,316.89$ & $153,759.28$ & $589,952.43$ & $1,405,824.83$ & $1,670,003.61$ & $558,708.65$ & $242,269.02$ & $279,550.78$ \\
\hline 24 & 0.00 & 0.00 & 0.00 & 0.00 & 0.00 & 0.00 & 0.00 & 0.00 & 0.00 \\
\hline 25 & 0.00 & 0.00 & 0.00 & 0.00 & 0.00 & 0.00 & 0.00 & 0.00 & 0.00 \\
\hline 26 & 0.00 & 0.00 & 0.00 & 0.00 & 0.00 & 0.00 & 0.00 & 0.00 & 0.00 \\
\hline 27 & 0.00 & 0.00 & 0.00 & 0.00 & 0.00 & 0.00 & 0.00 & 0.00 & 0.00 \\
\hline 28 & 0.00 & 0.00 & 0.00 & 0.00 & 0.00 & 0.00 & 0.00 & 0.00 & 0.00 \\
\hline 29 & $-4,659.34$ & $-5,768.39$ & $-26,357.20$ & $-12,277.40$ & $-6,507.98$ & $-6,769.17$ & $-105,730.51$ & $-2,261.40$ & -790.95 \\
\hline 30 & $1,500.62$ & $1,790.26$ & $2,077.48$ & $6,815.39$ & $19,087.45$ & $9,756.75$ & -328.52 & $3,687.82$ & 20,741.91 \\
\hline 31 & $-30,285.73$ & $5,405.60$ & $7,475.43$ & $-30,740.44$ & -97,078.24 & $24,080.91$ & $-18,351.97$ & -914.08 & $15,347.24$ \\
\hline 32 & 0.00 & 0.00 & 0.00 & 0.00 & 0.00 & 0.00 & 0.00 & 0.00 & 0.00 \\
\hline 33 & $56,350.42$ & $36,656.25$ & $51,298.86$ & $249,371.64$ & 2,311,717.72 & $109,842.85$ & $151,441.74$ & $76,693.85$ & $38,718.61$ \\
\hline TOTAL & $747,864.54$ & $1,206,820.59$ & $470,577.31$ & $2,422,300.27$ & $7,447,141.08$ & $2,943,685.73$ & $1,596,469,59$ & $585,342.21$ & $802,121,33$ \\
\hline
\end{tabular}




\begin{tabular}{|c|c|c|c|c|c|c|c|c|c|}
\hline SUBSECTOR & 10 & 11 & 12 & 13 & 14 & 15 & 16 & 17 & 18 \\
\hline 1 & 0.06 & 0.16 & 0.00 & 0.00 & 0.00 & 37.41 & 0.00 & 7.09 & 7.76 \\
\hline 2 & 1.75 & 0.71 & 0.00 & 0.00 & 0.00 & 0.03 & 0.00 & 0.00 & 0.0 \\
\hline 3 & $22,958.64$ & $5,922.74$ & 199.66 & $6,903.02$ & $14,126.58$ & $11,468.33$ & $3,443.01$ & $25,112.09$ & $10,063.98$ \\
\hline 4 & 700.19 & 28.05 & 9.78 & 38.06 & $6,201.92$ & $9,496.42$ & 157.85 & 579.80 & 608.17 \\
\hline 5 & $76,295.24$ & $15,666.00$ & $2,009.96$ & $20,995.70$ & $10,438.03$ & $33,152.97$ & $7,292.01$ & $76,004.34$ & $40,508.07$ \\
\hline 6 & $8,457.01$ & $3,968.85$ & 212.99 & $4,517.32$ & $2,881.55$ & $16,985.22$ & $1,079.30$ & $12,603.21$ & $10,449 \cdot 10$ \\
\hline 7 & $4,012.14$ & $4,246.55$ & 281.65 & $3,491.47$ & $2,763.04$ & $5,527.98$ & 705.08 & $2,273.26$ & $3,499.47$ \\
\hline 8 & $8,163.58$ & $6,574.01$ & 568.16 & $4,886.02$ & $7,564.76$ & $3,198.34$ & $1,035.42$ & $2,357.57$ & $3,922.03$ \\
\hline 9 & $15,021.85$ & $8,929.21$ & 808.66 & $5,387.82$ & $2,861.25$ & $1,069.01$ & 898.01 & $3,818.12$ & 757.76 \\
\hline 10 & $31,886.74$ & $10,887.03$ & $1,994.32$ & $5,538.84$ & $6,801.63$ & $4,145.50$ & $1,660.53$ & $4,210.66$ & $19,509.08$ \\
\hline 11 & $28,011.52$ & $32,299.49$ & $6,046.95$ & $16,075.26$ & $10,587.53$ & $19,622.84$ & $2,178.24$ & $7,420.66$ & $9,562.25$ \\
\hline 12 & $2,555.85$ & 760.23 & $7,621.59$ & $1,758.77$ & 739.18 & 561.74 & 268.08 & $2,163.26$ & 818.52 \\
\hline 13 & $11,261.85$ & $26,961.00$ & $3,450.86$ & $17,649.40$ & $7,836.72$ & $9,408.38$ & $4,309.64$ & $33,747.74$ & $13,411.50$ \\
\hline 14 & 42.03 & 614.22 & 0.00 & 0.07 & 385.70 & 9.17 & 166.05 & 0.00 & 1.25 \\
\hline 15 & 0.00 & 0.00 & 0.00 & 0.00 & 0.00 & 0.00 & 0.00 & 0.00 & 0.00 \\
\hline 16 & 27.62 & 0.00 & 0.00 & 3.20 & 0.00 & 0.00 & 89.67 & 1.40 & 80 \\
\hline 17 & 997.42 & 998.89 & 359.31 & $3,558.25$ & $3,181.78$ & $2,711.12$ & 315.65 & 474.74 & $1,240.88$ \\
\hline 18 & $3,679.65$ & $2,451.84$ & 91.73 & $1,106.24$ & $1,925.37$ & $5,888.70$ & $1,228.76$ & $4,452.54$ & $6,236.73$ \\
\hline 19 & 2.02 & 0.00 & 0.00 & 0.13 & 0.00 & 0.00 & 0.00 & 0.00 & 保 \\
\hline 20 & $33,021.44$ & $102,730.86$ & $13,625.76$ & $314,720.31$ & $571,074.43$ & $236,149.98$ & $17,064.10$ & $82,965.58$ & $135,765.25$ \\
\hline 21 & $5,494.29$ & $3,524.88$ & 0.00 & 0.00 & $75,005.93$ & $44,508.13$ & $1,840.53$ & $10,718.66$ & 000 \\
\hline 22 & 736.84 & $2,347.38$ & 496.42 & $6,720.34$ & $13,639.88$ & $4,129.35$ & 539.36 & $2,297.31$ & 633.35 \\
\hline 23 & $1,712,665.94$ & $207,073.16$ & $71,336.86$ & $124,706.61$ & $46,295.78$ & $50,910.68$ & $45,093.80$ & $229,894.37$ & $176,006.80$ \\
\hline 24 & 0.00 & 0.00 & 0.00 & 0.00 & 0.00 & 0.00 & 0.00 & 0.00 & 0.00 \\
\hline 25 & 0.00 & 0.00 & 0.00 & 0.00 & 0.00 & 0.00 & 0.00 & 0.00 & 0.00 \\
\hline 26 & 0.00 & 0.00 & 0.00 & 0.00 & 0.00 & 0.00 & 0.00 & 0.00 & \\
\hline 27 & 0.00 & 0.00 & 0.00 & 0.00 & 0.00 & 0.00 & 0.00 & 0.00 & 0.00 \\
\hline 28 & 0.00 & 0.00 & 0.00 & 0.00 & 0.00 & 0.00 & 0.00 & 0.00 & .00 \\
\hline 29 & $-10,342.50$ & $-1,774.49$ & -465.08 & -824.98 & $-1,188.29$ & $-1,812.68$ & -465.88 & $-2,433.30$ & $-3,015.45$ \\
\hline 30 & $2,001.05$ & $1,028.07$ & 438.82 & $3,543.47$ & $2,072.43$ & $1,396.66$ & 552.65 & $2,591.30$ & 994.71 \\
\hline 31 & $12,985.48$ & $11,374.05$ & $-11,176.62$ & $26,272.83$ & $-56,746.05$ & $-29,563.37$ & $-2,850.76$ & $-8,963.71$ & $5,882.51$ \\
\hline 32 & 0.00 & 0.00 & 0.00 & 0.00 & 0.00 & 0.00 & 0.00 & 0.00 & \\
\hline 33 & $19,400.81$ & $10,814.33$ & 586.40 & $10,013.53$ & $8,615.90$ & $25,133.53$ & $2,543.35$ & $18,977.64$ & $32,358.11$ \\
\hline TOTAL & $1,990,038.52$ & $457,427.24$ & $98,498.20$ & $577,061.69$ & $737,065.06$ & $454,135.46$ & $89,144.44$ & $511,274.34$ & $469,221.81$ \\
\hline
\end{tabular}




\begin{tabular}{|c|c|c|c|c|c|c|c|c|}
\hline SUBSECTOR & 19 & 20 & 21 & 22 & 23 & 24 & 25 & 26 \\
\hline 1 & 0.00 & 0.00 & 0.00 & 0.00 & 0.00 & 0.00 & $159,989.10$ & 0.00 \\
\hline 2 & 0.00 & 0.00 & 0.00 & 0.00 & 0.00 & 0.00 & 0.00 & 0.00 \\
\hline 3 & $15,462.37$ & 0.00 & 0.00 & 0.00 & 0.00 & 0.00 & $131,012.07$ & 0.00 \\
\hline 4 & $3,972.53$ & 0.00 & 0.00 & 0.00 & 0.00 & 0.00 & 0.00 & 0.00 \\
\hline 5 & $63,123.04$ & 0.00 & 0.00 & 0.00 & 0.00 & 0.00 & $3,108,803.96$ & 0.00 \\
\hline 6 & $18,300.89$ & 0.00 & 0.00 & 0.00 & 0.00 & 0.00 & $1,361,743.52$ & 0.00 \\
\hline 7 & $17,597.60$ & 0.00 & 0.00 & 0.00 & 0.00 & 0.00 & $877,436.16$ & 0.00 \\
\hline 8 & $14,056.69$ & 0.00 & 0.00 & 0.00 & 0.00 & 0.00 & $308,279.86$ & 0.00 \\
\hline 9 & $20,361.88$ & 0.00 & 0.00 & 0.00 & 0.00 & 0.00 & $429,766.59$ & 0.00 \\
\hline 10 & $7,296.36$ & 0.00 & 0.00 & 0.00 & 0.00 & 0.00 & $1,310,446.32$ & 0.00 \\
\hline 11 & $22,032.95$ & 0.00 & 0.00 & 0.00 & 0.00 & 0.00 & $49,048.93$ & 0.00 \\
\hline 12 & 389.92 & 0.00 & 0.00 & 0.00 & 0.00 & 0.00 & 0.00 & 0.00 \\
\hline 13 & $11,098.56$ & 0.00 & 0.00 & 0.00 & 0.00 & 0.00 & $32,189.33$ & 0.00 \\
\hline 14 & 81.04 & 0.00 & 0.00 & 0.00 & 0.00 & 0.00 & $195,708.57$ & 0.00 \\
\hline 15 & 0.00 & 0.00 & 0.00 & 0.00 & 0.00 & 0.00 & $240,477.45$ & 0.00 \\
\hline 16 & 904.29 & 0.00 & 0.00 & 0.00 & 0.00 & 0.00 & $83,266.09$ & 0.00 \\
\hline 17 & $20,382.62$ & 0.00 & 0.00 & 0.00 & 0.00 & 0.00 & $329,756.25$ & 0.00 \\
\hline 18 & $6,124.12$ & 0.00 & 0.00 & 0.00 & 0.00 & 0.00 & $288,039.08$ & 0.00 \\
\hline 19 & 0.00 & 0.00 & 0.00 & 0.00 & 0.00 & 0.00 & $5,948.71$ & 0.00 \\
\hline 20 & $499,463.11$ & 0.00 & 0.00 & 0.00 & 0.00 & 0.00 & 0.00 & 0.00 \\
\hline 21 & $96,970.03$ & 0.00 & 0.00 & 0.00 & 0.00 & 0.00 & 0.00 & 0.00 \\
\hline 22 & $13,284.32$ & 0.00 & 0.00 & 0.00 & 0.00 & 0.00 & 0.00 & 0.00 \\
\hline 23 & $3,640.04$ & 0.00 & 0.00 & 0.00 & 0.00 & 0.00 & 0.00 & 0.00 \\
\hline 24 & 0.00 & 0.00 & 0.00 & 0.00 & $8,737,034.57$ & 0.00 & 0.00 & 0.00 \\
\hline 25 & 0.00 & 0.00 & 0.00 & 0.00 & 0.00 & 0.00 & 0.00 & $8,911,855.97$ \\
\hline 26 & 0.00 & $4,408,958.03$ & $423,709.09$ & $136,617.04$ & 0.00 & $6,253,723.68$ & 0.00 & 0.00 \\
\hline 27 & 0.00 & 0.00 & 0.00 & 0.00 & 0.00 & 0.00 & 0.00 & 0.00 \\
\hline 28 & 0.00 & 0.00 & 0.00 & 0.00 & 0.00 & $571,642.98$ & 0.00 & $581,388.35$ \\
\hline 29 & $-7,642.27$ & 0.00 & 0.00 & 0.00 & 0.00 & 0.00 & 0.00 & $435,664.26$ \\
\hline 30 & $6,174.00$ & 0.00 & 0.00 & 0.00 & 0.00 & 0.00 & 0.00 & 0.00 \\
\hline 31 & $-77,613.49$ & 0.00 & 0.00 & 0.00 & 0.00 & 0.00 & 0.00 & 0.00 \\
\hline 32 & 0.00 & 0.00 & 0.00 & 0.00 & 0.00 & $1,814,024.86$ & 0.00 & $1,076,729.99$ \\
\hline 33 & $27,153.07$ & 0.00 & 0.00 & 0.00 & 0.00 & $97,698.22$ & 0.00 & $217,383.62$ \\
\hline TOTAL & $782,613.69$ & $4,408,958.03$ & $423,709.09$ & $136,617.04$ & $8,737,034.57$ & $8,737,089.74$ & $8,911,912.00$ & $11,223,022.19$ \\
\hline
\end{tabular}




\begin{tabular}{|c|c|c|c|c|c|c|c|c|}
\hline SUBSECTOR & 27 & 28 & 29 & 30 & 31 & 32 & 33 & TOTAL \\
\hline 1 & 0.00 & 0.00 & 0.00 & 0.00 & 0.00 & $82,470.46$ & $79,887.54$ & $747,864.54$ \\
\hline 2 & 0.00 & 0.00 & 0.00 & 0.00 & 0.00 & $165,951.32$ & $127,761.89$ & $1,206,820.59$ \\
\hline 3 & 0.00 & 0.00 & 0.00 & 0.00 & 0.00 & 0.00 & $40,522.10$ & $470,577.31$ \\
\hline 4 & 11.70 & 0.00 & 0.00 & 0.00 & 0.00 & $1,522,518.41$ & $688,765.09$ & $2,422,300.27$ \\
\hline 5 & 945.15 & 0.00 & 0.00 & 0.00 & 0.00 & $342,758.96$ & $783,420.34$ & 7,447,141.08 \\
\hline 6 & 0.00 & 0.00 & 0.00 & 0.00 & 0.00 & $262,469.10$ & $521,695.08$ & $2,943,685.73$ \\
\hline 7 & 0.00 & 0.00 & 0.00 & 0.00 & 0.00 & $100,089.73$ & $323,846.53$ & $1,596,469,59$ \\
\hline 8 & 32.62 & 0.00 & 0.00 & 0.00 & 0.00 & $4,889.51$ & $84,513.99$ & $585,342.21$ \\
\hline 9 & $1,312.99$ & 0.00 & 0.00 & 0.00 & 0.00 & 0.00 & $111,442.97$ & $802,121.33$ \\
\hline 10 & 7.13 & 0.00 & 0.00 & 0.00 & 0.00 & $38,997.22$ & $357,278.63$ & $1,990,038.52$ \\
\hline 11 & $6,964.56$ & 0.00 & 0.00 & 0.00 & 0.00 & 510.92 & $16,974.87$ & $457,427.24$ \\
\hline 12 & 0.00 & 0.00 & 0.00 & 0.00 & 0.00 & 0.00 & $-3,340.33$ & $98,498.20$ \\
\hline 13 & 0.00 & 0.00 & 0.00 & 0.00 & 0.00 & 0.00 & $-1,528.55$ & $577,061.69$ \\
\hline 14 & $265,549.97$ & 0.00 & 0.00 & 0.00 & 0.00 & 0.00 & $270,990.91$ & $737,065.06$ \\
\hline 15 & $213,656.81$ & 0.00 & 0.00 & 0.00 & 0.00 & 0.00 & 1.19 & $454,135.46$ \\
\hline 16 & $3,821.11$ & 0.00 & 0.00 & 0.00 & 0.00 & 0.00 & -0.11 & $89,144.44$ \\
\hline 17 & 0.00 & 0.00 & 0.00 & 0.00 & 0.00 & 0.00 & $111,595.17$ & $511,274.34$ \\
\hline 18 & 0.00 & 0.00 & 0.00 & 0.00 & 0.00 & 0.00 & $95,280.99$ & $469,221.81$ \\
\hline 19 & $775,752.70$ & 0.00 & 0.00 & 0.00 & 0.00 & 0.00 & 2.84 & $782,613.69$ \\
\hline 20 & 0.00 & 0.00 & 0.00 & 0.00 & 0.00 & 0.00 & $258,429.07$ & $4,408,958.03$ \\
\hline 21 & 0.00 & 0.00 & 0.00 & 0.00 & 0.00 & 0.00 & $56,306.92$ & $423,709,09$ \\
\hline 22 & 0.00 & 0.00 & 0.00 & 0.00 & 0.00 & 0.00 & 0.86 & $136,617.04$ \\
\hline 23 & 0.00 & 0.00 & 0.00 & 0.00 & 0.00 & 0.00 & $-51,088.39$ & $8,737,034.57$ \\
\hline 24 & 0.00 & 0.00 & 0.00 & 0.00 & 0.00 & 0.00 & 55.17 & $8,737,089.74$ \\
\hline 25 & 0.00 & 0.00 & 0.00 & 0.00 & 0.00 & 0.00 & 56.03 & $8,911,912.00$ \\
\hline 26 & 0.00 & 0.00 & 0.00 & 0.00 & 0.00 & 0.00 & 14.34 & $11,223,022.19$ \\
\hline 27 & 0.00 & $1,153,031.32$ & $447,354.79$ & $88,177.66$ & $-277,936.83$ & 0.00 & 13.76 & $1,410,640.71$ \\
\hline 28 & 0.00 & 0.00 & 0.00 & 0.00 & 0.00 & 0.00 & 0.00 & $1,153,031,32$ \\
\hline 29 & 0.00 & 0.00 & 0.00 & 0.00 & 0.00 & $19,835.18$ & $192,942.63$ & $447,354.79$ \\
\hline 30 & 0.00 & 0.00 & 0.00 & 0.00 & 0.00 & 0.00 & $2,255.35$ & $88,177.66$ \\
\hline 31 & 0.00 & 0.00 & 0.00 & 0.00 & 0.00 & 0.00 & $-22,476.42$ & $-277,936.83$ \\
\hline 32 & $142,585.97$ & 0.00 & 0.00 & 0.00 & 0.00 & 0.00 & -0.05 & $3,033,340.78$ \\
\hline 33 & 0.00 & 0.00 & 0.00 & 0.00 & 0.00 & $492,849.96$ & $52,094.24$ & $4,097,714.65$ \\
\hline TOTAL & $1,410,640.71$ & $1,153,031.32$ & $447,354.79$ & $88,177.66$ & $-277,936.83$ & $3,033,340.78$ & $4,097,714.65$ & \\
\hline
\end{tabular}

Fuente: Elaboración propia con datos del INEGI 2012. 


\section{ANÁLISIS ESTRUCTURAL}

\subsection{Multiplicadores generalizados}

La elaboración de este modelo es la generación de una matriz de multiplicadores generalizados, en lo sucesivo MMG, para obtenerla se toma como base la MCSMEX12.

Una MMG se concibe como una generalización de los modelos tradicionales de insumo-producto de Leontief, una vez que se realiza la bipartición en las cuentas donde el primer subconjunto es considerado endógeno, donde sus recursos y empleos son aquellos que van a determinarse; el segundo subconjunto, exógeno, contiene las cuentas cuyos ingresos se consideran fijos, de acuerdo con Cardenete (2000) a estas también se les conoce como variables de política.

Dado que en la MCSMEX12 el total de ingresos es igual al total de gastos para cada una de sus n cuentas, tenemos:

$$
\boldsymbol{Y}_{i}=\sum_{j-1}^{n} Y_{i j}=\sum_{j-1}^{n} Y_{j i}
$$

Indica que $\boldsymbol{Y}_{i}$ es el ingreso del subsector i, y $\boldsymbol{Y}_{i j}$ es el flujo del ingreso percibido por la cuenta i del subsector $\mathrm{j}$.

Donde:

$\boldsymbol{Y}_{i}=$ Es el ingreso total de la cuenta $\mathrm{i}$.

$Y_{i j}=$ Es el ingreso de la cuenta i obtenido de la cuenta j.

$Y_{j i}=$ Son los gastos del sector $\mathrm{i}$ en el sector $\mathrm{j}$.

Ahora bien, si definimos los coeficientes de gasto de la institución $\mathrm{j}$ $\left(a_{i j}\right)$ como el ingreso de la institución i derivado de la institución $\mathrm{j}$, dividido por el total de la cuenta i, tenemos:

$$
a_{i j}=\frac{Y_{i j}}{Y_{i}}
$$


Inmediatamente sabemos:

$$
\boldsymbol{Y}_{i}=\sum_{j-1}^{N}\left(\frac{Y_{i j}}{Y_{i}}\right) Y_{j}=\sum_{j-1}^{N} a_{i j} Y_{j}=\sum_{j-1}^{M} a_{i j} Y_{j}+\sum_{j-M+1}^{N} a_{i j} Y_{j}
$$

Donde:

$\sum_{j-1}^{M} a_{i j} Y_{j} \quad=$ recolecta el impacto de los ingresos de los subsectores endógenos.

$\sum_{j-M+1}^{N} a_{i j} Y_{j}=$ recolecta el impacto de los ingresos de los subsectores exógenos.

Matricialmente se observa de la manera siguiente:

$$
Y_{m}=A_{m m} Y_{m}+A_{m n} Y_{n}
$$

Donde:

$Y_{m}, Y_{n}=$ vectores de ingreso de las cuentas endógenas y exógenas.

$A_{m m}, A_{m n}=$ ubmatrices obtenidas al separar la matriz de coeficientes de gasto A de acuerdo con la categorización de instituciones endógenas y exógenas adoptada.

Se tiene así:

$$
[A]=\left[a_{i j}\right]=\left[\frac{A_{m m} A_{m n}}{A_{n m}, A_{n n}}\right]
$$

Si expresamos $x_{m}\left(A_{m m} Y_{n}\right)$ el vector de ingresos exógenos dirigidos a cada una de las cuentas endógenas obtenemos: 


$$
Y_{m}=\left(1-A_{m m}\right)^{-1} x_{m}=M x_{m}
$$

Donde:

$\boldsymbol{M}=$ matriz de multiplicadores generalizados.

Es M la inversa de Leontief cuando las instituciones endógenas incluyen sólo las actividades productivas, $\mathrm{M}$ mantiene la interpretación tradicional en donde los elementos de la columna j representan el impacto de un aumento unitario en el ingreso exógeno de la cuenta j sobre los ingresos de cada cuenta endógena y los elementos en la diagonal principal son iguales o mayores a 1, Núñez (2003).

Por otra parte, tenemos que el impacto de variaciones unitarias en el ingreso de la cuenta exógena 1 se obtiene a partir del empleo de la matriz de coeficientes de gasto $A_{m m}$; por lo tanto los cambios en los ingresos exógenos dirigidos a cada cuenta endógena es:

$$
\Delta x_{m}=a_{l} \Delta Y_{l}
$$

Donde:

$a_{l}=$ vector columna de la matriz $A_{m n}$ correspondiente a la cuenta

Si el aumento es igual a 1 el impacto sobre los ingresos de las cuentas endógenas es:

$$
\Delta Y_{m}=M a_{l}
$$

Por consiguiente, la variación del ingreso de la cuenta endógena $\mathrm{i}$ causada por un aumento unitario del ingreso de la cuenta exógena 1 es:

$$
\Delta Y_{m}=\sum_{j=i}^{M} m_{i j} a_{i l}
$$


De acuerdo con Núñez y Polo (2010) lo anterior se puede denotar como una suma de los elementos de la fila i de M multiplicados por el correspondiente coeficiente de gastos de la columna 1 de la matriz, donde estos coeficientes son normalizados, de tal forma que su suma sea 1 cuando algunas de las entradas de la columna 1 de la matriz no son nulas.

\subsubsection{Limitación del modelo}

La limitación más importante está dada porque es un modelo de precios fijos, lo cual implica que un cambio en el precio de los bienes se traslada por completo hacia adelante, lo que es equivalente a que los precios de los factores primarios son fijos. Esta limitación es perfectamente superada con el tratamiento de modelos de equilibrio general aplicado de precios.

Al partir de la MCSMEX12 se definen como endógenos los $19 \mathrm{sec}-$ tores productivos (1 al 19), el trabajo, contribuciones sociales y otras contribuciones (20 al 22), el capital (23), sociedades (24), consumo privado (25) y los hogares (26); se dejan como exógenas al gobierno (27), ISR (28), impuestos sobre bienes y servicios netos de subsidios (29), impuestos netos de subsidios sobre la producción (30), OIP (31), A-I (32) resto del mundo (33).

Se procede a los cálculos con base a la información anterior y se tiene como resultado la matriz de propensiones medias al gasto y finalmente la matriz M o de MMG, mismas que pueden consultarse en el anexo 1.

La MMG permite evaluar los efectos de cambios exógenos sobre las cuentas endógenas del sistema económico en estudio. Una de las interpretaciones que se puede dar a las columnas de la MMG es cómo el efecto de una inyección unitaria exógena sobre cada una de las cuentas endógenas se propaga, dicha inyección exógena puede ser distribuida entre las cuentas endógenas de distintos modos.

De la MMG un ejemplo es si la demanda por el primer subsector de la economía aumenta, es decir, si la agricultura aumenta esta tendrá que incrementar sus insumos para poder satisfacer la nueva demanda, por lo que los efectos de tal evento serán los siguientes: 
- La minería y la generación de transmisión de energía eléctrica deberán incrementar su producción en $\$ 0.10$ y $\$ 0.06$ respectivamente, la industria manufacturera $\$ .87$, comercio y transporte $\$ 0.28$ y $\$ 0.14$, el trabajo $\$ 0.40$, las sociedades y los hogares $\$ 1.32$ y $\$ 1.36$, así sucesivamente con el resto de las cuentas hasta tener un efecto multiplicador de $\$ 8.72$.

- Los efectos multiplicadores más grandes se dan en los servicios educativos con $\$ 10.65$, seguido de las actividades legislativas con $\$ 10.53$ y corporativos con $\$ 10.24$. Le siguen los servicios de salud y de asistencia social y servicios de esparcimiento, culturales y deportivos y otros servicios recreativos con $\$ 9.90$ y $\$ 9.28$. Por su parte, las cuentas que menor efecto multiplicador tienen son el capital con $\$ 7.89$, las sociedades $\$ 6.89$ y la industria manufacturera con $\$ 6.66$.

Es importante resaltar que esta es la estructura de acuerdo con la aplicación del modelo de multiplicadores generalizados para la economía mexicana en el año 2012, sin embargo, es posible observar los grandes cambios si se tiene la oportunidad de hacer una inyección unitaria exógena homogénea.

\subsection{Aumento unitario exógeno homogéneo (AUEH)}

Un aumento unitario exógeno puede ser distribuido de distintos modos entre las cuentas endógenas. A manera de efectuar un aumento unitario exógeno, y saber cómo se distribuye entre las cuentas endógenas al suponer que está dado por la media de los elementos de las filas de la MMG, es entonces que se considera que si:

$$
Y_{m}=M x_{m}
$$

Donde:

$Y_{m}=$ Ingreso

$M=$ Matriz de cuentas endógenas

$x_{m}=$ Vector de cuentas exógenas 
Se tiene claro, entonces, que el cambio en el ingreso de las cuentas endógenas ocasionado por una inyección a través del vector de cuentas exógenas $x_{m}$, está dado por $\Delta Y_{m}=M \Delta x_{m}$, de modo que para una inyección exógena precisamente igual a la unidad: $\Delta x_{m}=\left(\Delta x_{1} \ldots \Delta x_{m}\right)$ dado que $0 \leq \Delta x_{i} \leq 1$ tal que $\sum \Delta x_{m}=1$

Se tiene así que un $\mathrm{AUEH}$

$\Delta Y_{m}=M\left(\frac{1}{m} \ldots \frac{1}{m}\right)=\bar{x} M M G$ (media de los elementos de las filas de la $\left.M M G\right)$

Donde: $\mathrm{x}^{-}$

$\Delta Y_{m}=$ Aumento Unitario Exógeno

$M=\quad$ Matriz de cuentas endógenas,

$M M G=$ Matriz de Multiplicadores Generalizados $\left(m_{i j}\right)$,

$m$ es el número de cuentas endógenas

Obsérvese el cuadro 7, que muestra un aumento unitario exógeno en cada uno de los sectores productivos de la economía mexicana.

Es así que los más beneficiados son los hogares, es decir, si la estructura económica mexicana tiene un aumento exógeno de una unidad, los hogares tendrán un aumento favorable de $\$ 1.56$, seguido del consumo privado $\$ 1.28$, las sociedades con $\$ 1.23$; en materia de sectores productivos es la industria manufacturera la que se beneficia más con un monto de $\$ 0.84$, seguido del comercio con $\$ 0.32$; servicios de esparcimiento culturales y deportivos y otros servicios recreativos quedan en las últimas posiciones con un beneficio de tan sólo $\$ 0.05$; la construcción y las actividades legislativas ocupan los lugares 25 y 26 de AUEH con tan sólo $\$ 0.47$ y $\$ 0.04$, respectivamente.

El efecto multiplicador total para un aumento unitario exógeno homogéneo (AUEH) es entonces de $\$ 8.86$, esto significa que la suma de toda la distribución del impacto por una unidad será por la cantidad antes mencionada. 


\section{Cuadro 7}

Aumento unitario exógeno homogéneo (AUEH)

\begin{tabular}{|c|c|}
\hline Cuenta & Homogéneo \\
\hline Agricultura, cría y explotación de animales, aprovechamiento forestal, pesca y caza & 0.1126 \\
\hline Minería & 0.1400 \\
\hline $\begin{array}{l}\text { Generación, transmisión y distribución de energía eléctrica, suministro de agua y de } \\
\text { gas por ductos al consumidor final }\end{array}$ & 0.0971 \\
\hline Construcción & 0.0467 \\
\hline Industrias manufactureras & 0.8470 \\
\hline Comercio & 0.3236 \\
\hline Transportes, correos y almacenamiento & 0.1994 \\
\hline Información en medios masivos & 0.1099 \\
\hline Servicios financieros y de seguros & 0.1329 \\
\hline Servicios inmobiliarios y de alquiler de bienes muebles e intangibles & 0.2647 \\
\hline Servicios profesionales, científicos y técnicos & 0.1007 \\
\hline Corporativos & 0.0561 \\
\hline Servicios de apoyo a los negocios y manejo de desechos y servicios de remediación & 0.1172 \\
\hline Servicios educativos & 0.0673 \\
\hline Servicios de salud y de asistencia social & 0.0729 \\
\hline Servicios de esparcimiento culturales y deportivos, y otros servicios recreativos & 0.0507 \\
\hline Servicios de alojamiento temporal y de preparación de alimentos y bebidas & 0.0934 \\
\hline Otros servicios excepto actividades gubernamentales & 0.0910 \\
\hline $\begin{array}{l}\text { Actividades legislativas, gubernamentales, de impartición de justicia y de } \\
\text { organismos internacionales y extraterritoriales }\end{array}$ & 0.0394 \\
\hline Trabajo & 0.5212 \\
\hline Contribuciones sociales efectivas a la seguridad social & 0.0679 \\
\hline Otras prestaciones sociales & 0.0499 \\
\hline Capital & 1.1942 \\
\hline Sociedades & 1.2326 \\
\hline Consumo privado & 1.2770 \\
\hline Hogares & 1.5598 \\
\hline Total & 8.8654 \\
\hline
\end{tabular}

Fuente: Elaboración propia. 


\subsubsection{Sectores clave}

Una vez construida la MMG es posible determinar los efectos de absorción o forward linkages (FL) desde las filas de la matriz. Este índice muestra el nivel de renta que se absorbe por las cuentas endógenas.

Por otra parte, con base en las columnas de la MMG, se obtiene el efecto total de una inyección exógena unitaria de renta sobre una cuenta endógena, sobre la renta de los agentes económicos; este efecto se conoce como difusión o backward linkages (BL), el cual refleja los rubros que resultan más significativos para recibir inyecciones externas, al provocar una mayor expansión de la renta sobre el total de la economía.

Lo anterior es posible determinar con la aplicación de las siguientes ecuaciones con base en Cardenete et al. (2005).

$$
\begin{aligned}
& F l_{i}=\frac{M_{i}}{\frac{1}{n} \sum_{j=1}^{n} \sum_{i=1}^{n} m_{i j}} \\
& B l_{i}=\frac{M_{j}}{\frac{1}{n} \sum_{j=1}^{n} \sum_{i=1}^{n} m_{i j}}
\end{aligned}
$$

Donde:

$M_{i}=$ suma de la $i$ - ésima fila de la matriz inversa

$M_{j}=$ suma de la $j$ - ésima columna de la matriz inversa

$m_{i j}=$ elementos de la matriz de multiplicadores lineales $M$

Una vez que se obtienen los índices FL y BL es posible establecer una relación entre ellos y se tiene como resultado la categorización de cuatro tipos de sectores en relación con la media $(\bar{x})$

La clasificación de estos sectores entonces es como se muestra en el cuadro 8 . 


\section{Cuadro 8}

Clasificación de los sectores con base en los FL y BL

\begin{tabular}{|c|c|c|}
\hline & $B L>\bar{x}(B L)$ & $B L<\bar{x}(B L)$ \\
\hline \multirow[b]{2}{*}{$F L>\bar{x}(F L)$} & Sectores claves & Sectores estratégicos \\
\hline & $\begin{array}{l}\text { Su principal característica son } \\
\text { los grandes efectos sobre la } \\
\text { economía total. Las políticas } \\
\text { económicas enfocadas en estos } \\
\text { sectores son transmitidas con } \\
\text { un mayor grado que el resto por } \\
\text { lo que activan de manera más } \\
\text { inmediata a la economía. }\end{array}$ & $\begin{array}{l}\text { Son proveedores de bienes de uso } \\
\text { intermedio para otros sectores, } \\
\text { por lo que al tomar decisiones de } \\
\text { precios y de producción para el } \\
\text { total de la economía, la estrategia } \\
\text { se fija en ellos. }\end{array}$ \\
\hline \multirow[b]{2}{*}{$F L<\bar{x}(F L)$} & Sectores impulsores & Sectores independientes \\
\hline & $\begin{array}{l}\text { Se caracterizan por su capacidad } \\
\text { de impulsar a otros sectores, } \\
\text { en otras palabras, difunden los } \\
\text { efectos de los choques exógenos } \\
\text { al resto de los sectores, sin } \\
\text { afectarse a sí mismos. }\end{array}$ & $\begin{array}{l}\text { Sus efectos en la economía } \\
\text { no son significativos, pero } \\
\text { tampoco reaccionan a los efectos } \\
\text { producidos por otros subsectores. }\end{array}$ \\
\hline
\end{tabular}

Fuente: Elaboración propia.

Con la información anterior es posible determinar los FL y BL, mismos que se presentan en el cuadro 9.

Del cuadro 9 se puede resaltar que los BL, o efectos de difusión, los encabezan los servicios educativos con un índice de 1.15, seguido por corporativos con 1.14 y actividades legislativas, gubernamentales y de impartición de justicia con un índice de 1.12, en otras palabras, estas cuentas provocan una mayor expansión de la renta sobre el total de la economía, por lo que se sugiere sean las que reciban más o mayores inyecciones externas.

El caso contrario es la industria manufacturera, que presenta un menor índice de difusión correspondiente a 0.79 , por lo que no se sugiere sea esta la que mayores inyecciones externa tenga.

Respecto a los FL tenemos que los sectores que mayor absorción tienen de la renta por las cuentas endógenas son: industria manufacturera con 2.86, comercio con 1.04 y servicios inmobiliarios y de alquiler con 0.81 . 


\section{Cuadro 9}

Backward Linkages y Forward Linkages para la economía mexicana 2012

\begin{tabular}{|l|c|c|}
\hline \multicolumn{1}{|c|}{ Sector } & $\begin{array}{c}\text { Backward } \\
\text { Linkages }\end{array}$ & $\begin{array}{c}\text { Forward } \\
\text { Linkages }\end{array}$ \\
\hline $\begin{array}{l}\text { Agricultura, cría y explotación de animales, aprovechamiento } \\
\text { forestal, pesca y caza }\end{array}$ & 0.9590 & 0.2732 \\
\hline Minería & 0.9958 & 0.3947 \\
\hline $\begin{array}{l}\text { Generación, transmisión y distribución de energía eléctrica, } \\
\text { suministro de agua y gas. }\end{array}$ & 0.8828 & 0.1871 \\
\hline Construcción & 0.9346 & 0.1356 \\
\hline Industrias manufactureras & 0.7947 & $\mathbf{2 . 8 6 3 4}$ \\
\hline Comercio & 1.0144 & $\mathbf{1 . 0 4 8 3}$ \\
\hline Transportes, correos y almacenamiento & 0.9767 & 0.5902 \\
\hline Información en medios masivos & 0.8855 & 0.2377 \\
\hline Servicios financieros y de seguros & 0.9271 & 0.3227 \\
\hline Servicios inmobiliarios y de alquiler de bienes muebles e intangibles & 1.0328 & $\mathbf{0 . 8 1 5 5}$ \\
\hline Servicios profesionales, científicos y técnicos & 0.9830 & 0.1743 \\
\hline Corporativos & $\mathbf{1 . 1 4 6 2}$ & 0.0434 \\
\hline $\begin{array}{l}\text { Servicios de apoyo a los negocios y manejo de desechos y servicios } \\
\text { de remediación }\end{array}$ & 0.9939 & 0.2351 \\
\hline Servicios educativos & $\mathbf{1 . 1 5 6 3}$ & 0.1295 \\
\hline Servicios de salud y de asistencia social & 1.0583 & 0.1356 \\
\hline $\begin{array}{l}\text { Servicios de esparcimiento culturales y deportivos, y otros servicios } \\
\text { recreativos }\end{array}$ & 1.0135 & 0.0442 \\
\hline $\begin{array}{l}\text { Servicios de alojamiento temporal y de preparación de alimentos y } \\
\text { bebidas }\end{array}$ & 0.9798 & 0.1981 \\
\hline Otros servicios excepto actividades gubernamentales & 0.9489 & 0.1860 \\
\hline $\begin{array}{l}\text { Actividades legislativas, gubernamentales, de impartición de } \\
\text { justicia ... }\end{array}$ & $\mathbf{1 . 1 2 7 2}$ & 0.0402 \\
\hline \multicolumn{1}{|c|}{ PROMEDIO } & $\mathbf{0 . 9 9 0 0}$ & $\mathbf{0 . 4 2 3 9}$ \\
\hline
\end{tabular}

Fuente: Elaboración propia.

Con la información del cuadro 8 es posible clasificar, con base en los BL y FL, los sectores productivos de la economía mexicana, como se observa en el cuadro 10 . 


\section{Cuadro 10}

Clasificación de los sectores de la economía mexicana en el año 2012

\begin{tabular}{|c|c|c|}
\hline & $B L>\bar{x}(B L)$ & $B L<\bar{x}(B L)$ \\
\hline \multirow[b]{2}{*}{$F L>\bar{x}(F L)$} & Sectores claves & Sectores estratégicos \\
\hline & $\begin{array}{l}\text { - Comercio } \\
\text { - Servicios inmobiliarios }\end{array}$ & $\begin{array}{l}\text { - Industria manufacturera } \\
\text { - Transporte, correo y almacenamiento. }\end{array}$ \\
\hline \multirow[b]{2}{*}{$F L<\bar{x}(F L)$} & Sectores impulsores & Sectores independientes \\
\hline & $\begin{array}{l}\text { - Actividades legislativas, } \\
\text { gubernamentales y de } \\
\text { organismos internacionales y } \\
\text { extraterritoriales. } \\
\text { - } \text { Minería } \\
\text { - Corporativos. } \\
\text { - Servicios de apoyo a los } \\
\text { negocios. } \\
\text { - Servicios de esparcimiento, } \\
\text { culturales y deportivos, y otros } \\
\text { - Servicios recreativos. } \\
\text { - Servicios de salud y de asistencia } \\
\text { social. } \\
\text { - Servicios educativos. }\end{array}$ & $\begin{array}{l}\text { Agricultura, cría y explotación de } \\
\text { animales, aprovechamiento forestal, } \\
\text { pesca y caza. } \\
\text { - Construcción. } \\
\text { - Generación, transmisión y } \\
\text { distribución de energía eléctrica. } \\
\text { - Información en medios masivos. } \\
\text { - Servicios profesionales, científicos y } \\
\text { técnicos. } \\
\text { - Otros servicios excepto actividades } \\
\text { gubernamentales. } \\
\text { - Servicios de alojamiento temporal } \\
\text { y de preparación de alimentos y } \\
\text { bebidas. } \\
\text { - Servicios financieros y de seguros. }\end{array}$ \\
\hline
\end{tabular}

Fuente: Elaboración propia.

Los sectores clave de la economía mexicana son el comercio y los servicios inmobiliarios, ambos pertenecen al tercer sector económico, servicios. Son los que tienen un mayor e inmediato efecto en la estructura económica nacional, por lo que deberían de estar incluidos como ejes principales en el plan nacional de desarrollo y, con ello, la política económica esté encaminada al desarrollo del país de una forma más acertada para la expansión del crecimiento económico.

El comercio se contabiliza a nivel nacional en dos rubros: al por mayor y al por menor, de acuerdo con el INEGI (2017) cada uno presenta un índice trimestral con año base de 2008, tanto al por mayor como al por menor el crecimiento de la actividad del primer trimestre de 2008 a 2014 
ha sido constante; sin embargo, del comercio al por menor, los gastos de consumo de bienes y servicios han tenido un importante alza en los gastos que son exclusivamente a través de internet, catálogos impresos, televisión y similares, como puede observarse en la gráfica 2.

\section{Gráfica 2}

Comercio al por menor, gastos de consumo de bienes y servicios

Comercio al por menor

Gastos por consumo de bienes y servicios

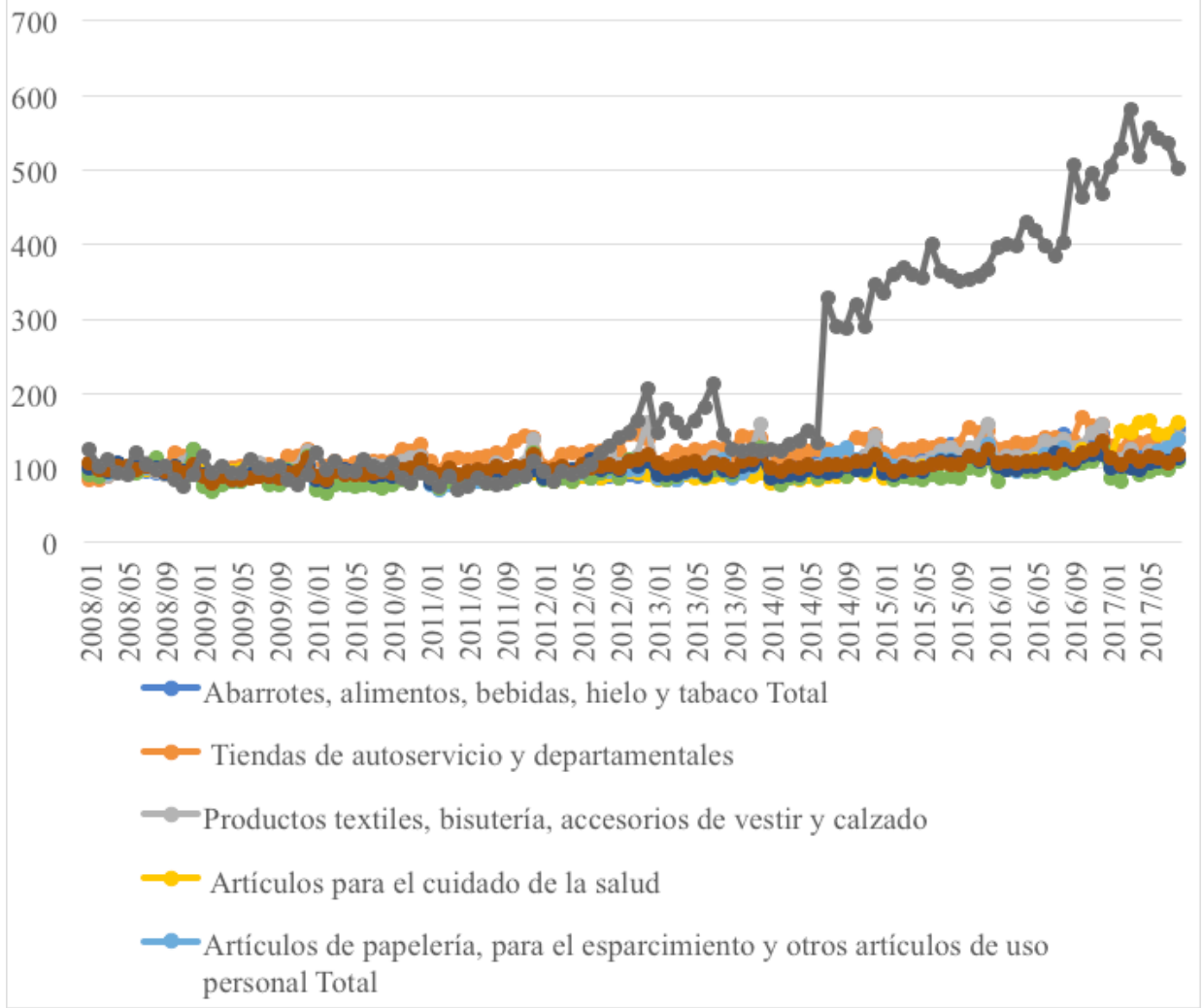


A este importante evento le siguen las tiendas de autoservicio y departamentales. El evento se presenta de forma similar con los ingresos, aunque la clasificación que presenta el INEGI no es exactamente la misma, las entradas más representativas son por las tiendas de autoservicio.

Lo anterior, nos lleva a la reflexión de que un sector tan importante como el comercio debe de tener un plan de acción, seguimiento en su instrumentación y desarrollo, debe integrarse como eje principal al plan nacional de desarrollo. Las estrategias deben considerar la actual posición de las tiendas de autoservicio nacional y las empresas que están encabezando los ingresos y egresos al por menor en estos rubros, así como las tendencias de las nacionales.

Respecto a los servicios inmobiliarios, también deben de ser incluidos en la agenda nacional con una supervisión cercana.

Los sectores estratégicos son entonces la industria manufacturera y de transporte, lo que representa el seguimiento de la tendencia del modelo económico mexicano en las últimas décadas, la estrategia se debe fijar en el plan nacional de desarrollo, en fortalecer sustentablemente estos sectores los que, al tomar decisiones de precios y de producción, son esenciales por proveer a otros sectores.

Los sectores impulsores, en correspondencia con la MMG, son las actividades legislativas, minería, corporativos, servicio de apoyo a los negocios, actividades de esparcimiento, culturales, servicios educativos y de salud, que proporcionan un mayor efecto multiplicador. Su importancia radica en que difunden los efectos de los choques exógenos al resto de los sectores sin afectarse a sí mismos.

Los sectores independientes son: agricultura, construcción, generación, transmisión y distribución de energía eléctrica, información en medios masivos, servicios profesionales, científicos y técnicos, otros servicios excepto actividades gubernamentales, servicios de alojamiento temporal y de preparación de alimentos y bebidas y servicios financieros y de seguros. Los efectos de estos sectores en la economía no son significativos, pero tampoco reaccionan a los efectos producidos por otros subsectores. No por ello dejan de ser importantes, por el contrario, en el caso de los servicios profesionales, científicos y técnicos valdría la pena estudiarlos en detalle 
para colocarlos al servicio del resto de la estructura y, entonces, sea un sector estratégico e incluso clave. Lo mismo sucede con la construcción y la generación, transmisión y distribución de energía eléctrica, que muy probablemente sean capitales que a la estructura económica nacional aportan una porción mínima y el resto viaja a otros países de origen.

\section{CONCLUSIONES}

Esta investigación se ha realizado con el mayor rigor técnico posible, con el objetivo de unificar los criterios para la elaboración de la MCSMEX12 y con ello tener una estructura bien definida de la economía mexicana para el año 2012, lo que se ha obtenido con la congruencia de los indicadores.

El primer producto de este trabajo es la MCSMEX12, la cual se pone a disposición con la finalidad de que otros investigadores cuenten con la base de datos para generar análisis multisectoriales más avanzados, como lo puede ser un modelo de precios preciso del equilibrio general aplicado para el año 2012 de la economía mexicana.

$\mathrm{Al}$ inicio de este documento la hipótesis que se aborda es que la industria manufacturera no es un sector clave de la economía mexicana, pese a tenerse una percepción contraria ya que esta ha sido la prioridad nacional por varias décadas, tal es el caso del presente plan nacional de desarrollo 2013-2018, que retoma a la industria manufacturera.

La hipótesis se confirma al detectar al comercio como un sector clave de la economía mexicana y, en correspondencia con los resultados expuestos en nuestro trabajo, debería tomar un papel principal en el plan nacional de desarrollo, bajo este esquema puede ser reforzado y favorecer su crecimiento sostenido para llegar a ser un motor de crecimiento económico en México. De la misma forma deben de tener una mayor regulación y seguimientos los servicios inmobiliarios, que también son un sector clave para México, al tener en cuenta que estamos en vías de desarrollo, la óptima regulación para este sector por los flujos que representa en la economía nación y, por ende, en la repercusión del mismo en el resto de los sectores. 
Los sectores de la economía que por su naturaleza representan un aporte de efecto multiplicador, impulsores son: las actividades legislativas, la construcción, los servicios corporativos, los servicios de esparcimiento y servicios educativos, principalmente.

Es indispensable entender la importancia de las actividades legislativas, gubernamentales, de impartición de justicia y de organismos internacionales y extraterritoriales en la estructura de la economía mexicana, como aquí se ha señalado son un sector impulsor, ya que transfiere los choques exógenos al resto de los sectores sin que este se vea afectado, requiriendo un cuidado y seguimiento particular en la administración de las mismas.

De la misma forma esta la construcción que, en las últimas décadas, ha modificado su forma de ejecución por la introducción de maquinaria que reemplaza el trabajo manual, así también intervienen las normas de seguridad para uso de suelo y construcción. A la par se encuentra la renovación del desarrollo de los servicios corporativos, los servicios de esparcimiento y servicios educativos, principalmente.

Los sectores estratégicos son, entonces, la industria manufacturera, transporte correo y almacenamiento, por lo que, en congruencia con los datos iniciales del panorama económico de México, el país centra su actividad económica en el sector terciario, claramente sostenido por una mayor actividad e intercambio intersectorial de subsectores que pertenecen al segundo grupo de actividades. Ahora bien, sin ser un sector clave la industria manufacturera que se convierta en un motor de crecimiento económico para el país, su importancia y la de los sectores de transporte, correo y almacenamiento radica que, al ser proveedores de bienes de uso intermedio para otros sectores, la estrategia de toma de decisiones de precios y de producción para el total de la economía, esta se debe fijar con base a estos.

Finalmente los sectores independientes son la agricultura, construcción, generación, transmisión y distribución de energía eléctrica, información en medios masivos, servicios profesionales, científicos y técnicos, otros servicios excepto actividades gubernamentales, servicios de alojamiento temporal y de preparación de alimentos y bebidas y servicios 
financieros y de seguros; los efectos de estos sectores en la economía no son significativos, pero tampoco reaccionan a los efectos producidos por otros subsectores.

Y por su importancia radica en la transformación que puede tener el país al integrarlos sostenidamente a la estructura económica, como es el caso de los servicios profesionales, científicos y técnicos, para colocarlos al servicio del resto de la estructura, y entonces sea un sector estratégico e incluso clave.

\section{REFERENCIAS}

Aguayo, E. et al. 2009. Analisis de la generación y redistribución del ingreso en México a través de una matriz de contabilidad social, Estudios Económicos, número extraordinario, pp. 225-311.

Albornoz, L. y R. Ortiz. 2016. Cuantificación de los efectos de la disminución de remesas internacionales dirigidas a las regiones urbanas y rurales de México en 2002 mediante el uso de una matriz de contabilidad social, Economía Teoría y Práctica, núm.45,http://www. revistas-conacyt.unam.mx/economiatyp/index.php/ETYP/ article/ view/50/244.

Barboza, I. et al. 2012. Matriz de contabilidad social 2004 para méxico, Colegio de Postgraduados: http://scielo.unam.mx/pdf/agro/v43n5/ v43n5a10.pdf.

Beltrán, L. et al. 2016. Análisis estructural de la economía mexicana para el año 2008, Ensayos Revista de Economía, XXXV(1):1-38.

Cardenete, M. et al. 2005. A structural analysis of a regional economy using a social accounting matrices: 1990-1999, Investigaciones Regionales, 5:113-138.

Cardenete, M. 2000. Modelos de equilibrio general aplicados a la economìa andaluza, tesis doctoral, Universidad de Huelva. 
Cardona, G. 2015. Diseño de una estrategia de desarrollo sostenible para el municipio de Aquismón, San Luis Potosi 2015-2025, tesis maestría, Instituto Politécnico Nacional.

Casares, E. et al. 2017. Las matrices de contabilidad social como base de datos y soporte de modelos multisectoriales, EconoQuantum, 14(1):119-142.

Chapa, J. y E. Rangel. 2010. Análisis de la estructura productiva y de ingreso-gasto del estado de Nuevo León para el año 2004, EconoQuantum, 6(2):125-381.

INEGI. 2015 . BIE, http://www.inegi.org.mx/sistemas/bie/.

Jaime, C. 1992. Construcción de una matriz de contabilidad social para México, 1989, tesis de maestría, El Colegio de México.

Kehoe et al. 1984. A general equilibrium model of domestic commerce in Mexico. Journal of Policy Modeling 6(1):1-28(1984).

Núñez, G. 2014. Macro matriz de contabilidad social de México para el año 2003, EconoQuantum, 11(2): 75-99.

.2003. Un análisis estructural y de equilibrio general de la economía, tesis de doctorado, Universidad Autónoma de Barcelona.

y V. Mendoza .2008.. Matriz de contabilidad social y análisis estructural de una economía rural: el ejido Los Lirios, municipio de Arteaga, Coahuila, México, Economía:Teoría y Práctica, 28:43-71.

Nuñez, G. y C. Polo. 2010. Una matriz de contabilidad social de México y un análisis estructural de la economía mexicana, Estudios Sociales, vol. 18 , núm 35 .

Parra, J. y O. Pino. 2012. Aplicación de método RAS y entropía cruzada para actualización de matrices insumo-producto, European Scientific Journal, 8(20): 49-61.

Pyatt, G. 1991. SAMs, the SNA and national accounting capabilities, The review of Income and Wealth, 37(2): 177-198. 
Pyatt, G. y E. Thorbecke. 1976. Planning techniques for a better future: A summary of a research project on planning for growth, redistribution and employment. International Labor Office, Ginebra.

Stone, R. 1961. Multiple classifications in social accounting, ISI conference, París.

1969. Contabilidad social y modelos económicos, Oikos-tau, Barcelona.

Thorbecke, E. (1988). The Impact of Stabilization and Structural Adjustment Measures and Reforms on Agriculture and Equity. Policy Reform and Equity: Extending the Benefits of Development, Institute for Contemporary Studies, San Francisco.

Yúnez, A. y S. González. 2008. Efectos multiplicadores de las actividades productivas en el ingreso y pobreza rural en México, El Trimestre Económico, 75(298-2):349-377. 


\section{ANEXO 1}

\section{Calculo de la matriz de multiplicadores generalizados}

$$
Y_{m}=\left(1-A_{m m}\right)^{-1} x_{m}=M_{x m}
$$

\section{Matriz de propensiones medias al gasto}

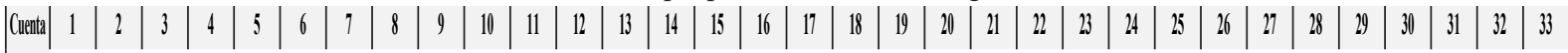

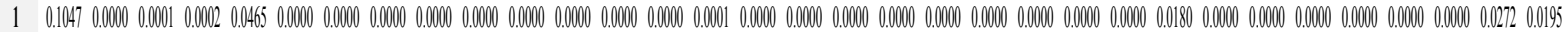

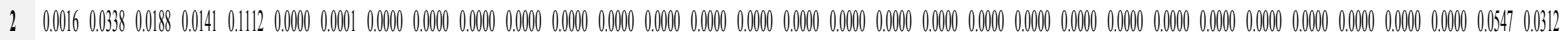

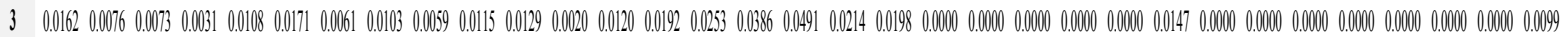

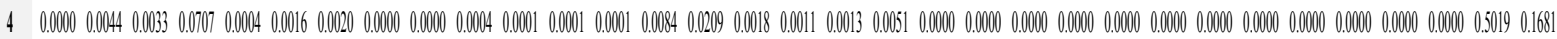

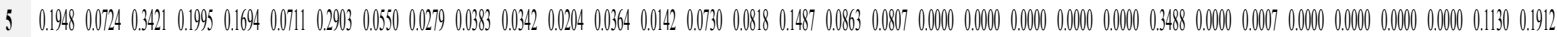

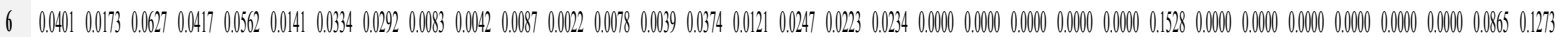



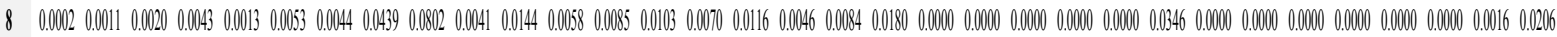

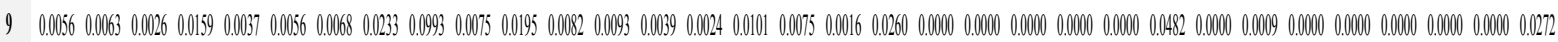

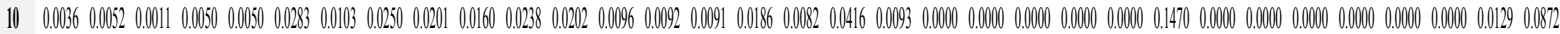

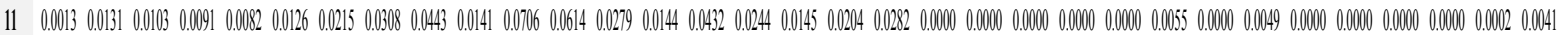

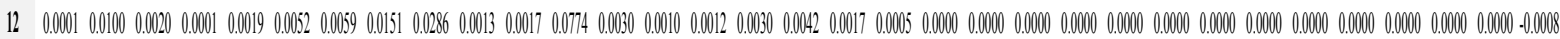

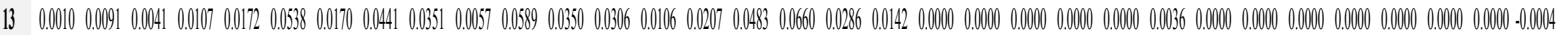

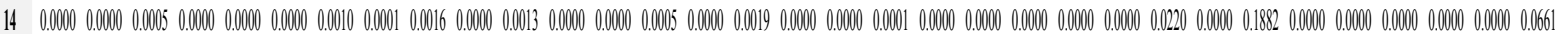

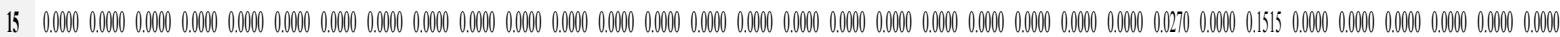

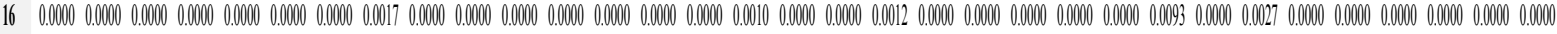

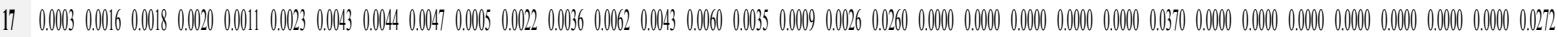

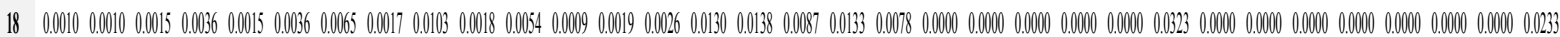

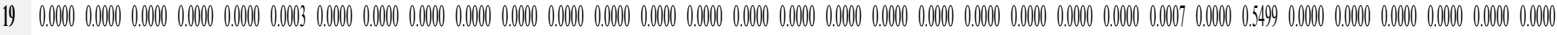

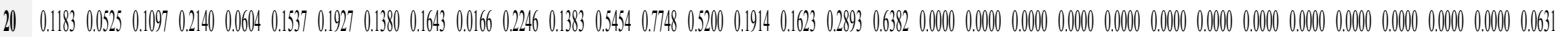

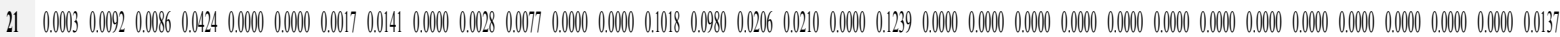

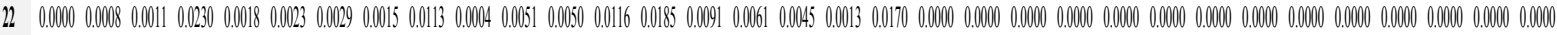

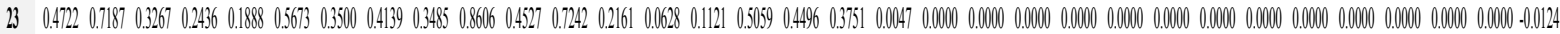

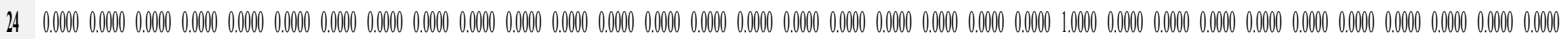

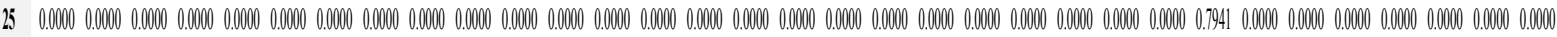

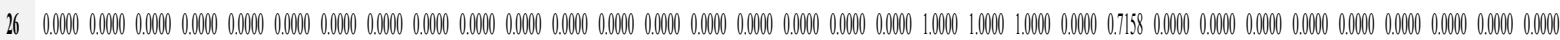

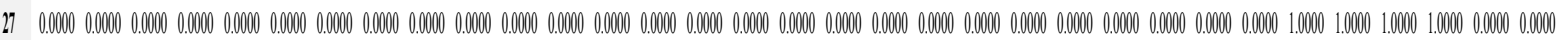

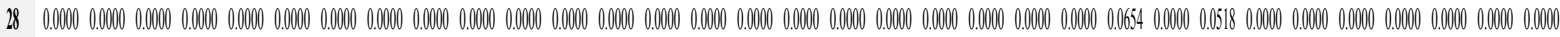

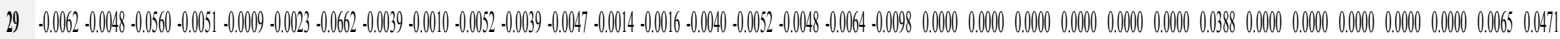

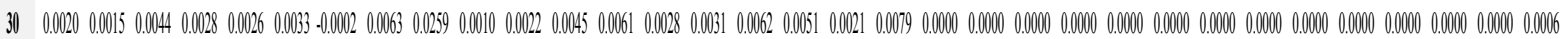

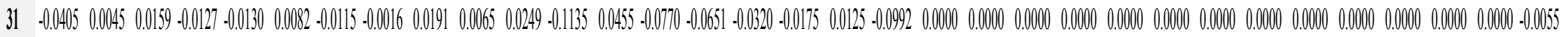

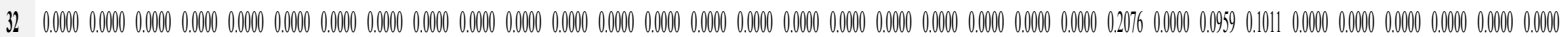

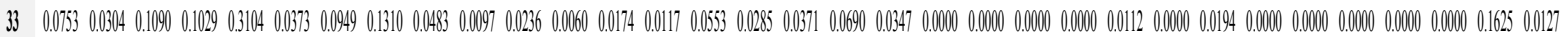

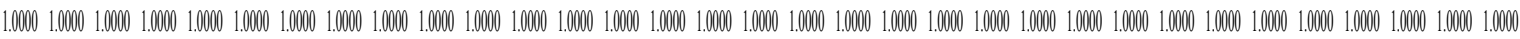

Fuente: Elaboración propia. 


\section{Matriz de multiplicadores generalizados}

\begin{tabular}{|c|c|c|c|c|c|c|c|c|c|c|c|c|c|c|c|c|c|c|c|c|c|c|c|c|c|c|c|}
\hline$(i-A)^{\Lambda}-1$ & 1 & 2 & 3 & 4 & 5 & 6 & 7 & 8 & 9 & 10 & 11 & 12 & 13 & 14 & 15 & 16 & 17 & 18 & 19 & 20 & 21 & 22 & 23 & 24 & 25 & 6 & Sumas \\
\hline 1 & 1.18 & 0.06 & 0.07 & 7 & 0.10 & 6 & 0.07 & 0.06 & 6 & 6 & 006 & 1 & 0.07 & 0.08 & 0.07 & 007 & 0.07 & 0.06 & 0.08 & Q & 0.08 & nele & n:G & 0.06 & 010 & (1) & 203 \\
\hline 2 & 0.10 & 112 & 013 & 0.12 & 0.19 & 0.09 & 0.11 & DQR & 0.08 & 0.08 & 0.08 & 0.09 & 0.09 & 11 & 10 & 0.09 & 0.10 & 0.09 & 0.11 & 10 & 0.10 & 10 & 0.07 & 0.07 & 0.13 & 10 & \\
\hline 3 & 0.0 & 0.05 & 1.05 & 15 & 0.04 & 0.06 & 0.05 & 05 & 0.05 & 0.05 & 0.06 & 0.05 & 0.06 & 08 & .08 & 0.08 & 0.09 & 0.07 & 0.08 & .05 & 0.05 & 05 & 0.04 & 0.04 & 0.07 & .05 & 250 \\
\hline 4 & 0.00 & 0.01 & 001 & 1.08 & 0.00 & 0.00 & 0.01 & 0.00 & 0.00 & 0.00 & 0.00 & 0.00 & 0.00 & 0.01 & .03 & 0.01 & 0.00 & 0.00 & 0.01 & .00 & 0.00 & 0.00 & 0.00 & 0.00 & 0.00 & 0.00 & \\
\hline 5 & 0.87 & 0.71 & 0.98 & 0.88 & 1.67 & 0.73 & 0.99 & 0.66 & 0.67 & 0.67 & 0.71 & 0.77 & 0.77 & 0.91 & 0.89 & 0.79 & 0.85 & 0.76 & 0.97 & 86 & 0.86 & 0.86 & 0.62 & 0.62 & 1.09 & .86 & \\
\hline 6 & 0.28 & 0.25 & 0.29 & 0.29 & 0.23 & 1.25 & 0.28 & 25 & 0.24 & 0.24 & 0.26 & 0.28 & 0.28 & 33 & 134 & 0.27 & 0.28 & 0.27 & 0.35 & Ju & 0.32 & 0.12 & LJ & 0.23 & 0.41 & $\sqrt{2}$ & \\
\hline 1 & 0.14 & 0.14 & 0.15 & 0.14 & 0.11 & 0.15 & 1.16 & 14 & 0.15 & 0.14 & 0.15 & 0.16 & 0.16 & 0.19 & 0.18 & 0.16 & 0.15 & 0.15 & 0.21 & 19 & 0.19 & 0.19 & 0.13 & 0.13 & 0.24 & 19 & \\
\hline 8 & 0.05 & 0.05 & 0.05 & 0.06 & 0.04 & 0.06 & 0.06 & 10 & 0.15 & 0.06 & 0.08 & 0.07 & 0.07 & 0.09 & .08 & (0) & 06 & 06 & 10 & .07 & 0.07 & 0.01 & WJ & .05 & 0.09 & 07 & \\
\hline 9 & 0.08 & 0.08 & 0.07 & 0.09 & 0.06 & 0.08 & 0.08 & 0.10 & 1.19 & 0.08 & 0.10 & 0.10 & 0.10 & 0.11 & 0.10 & 0.09 & 0.08 & 0.08 & 0.13 & 0.10 & 0.10 & 0.10 & 0.07 & 0.07 & 0.13 & 0.10 & \\
\hline 10 & 0.19 & 0.19 & 0.17 & 0.19 & 0.14 & 0.22 & 0.20 & 1 & 0.21 & 1.20 & 0.23 & 0.25 & 0.23 & 28 & 2) & $0.2 J$ & 0.21 & 0.24 & 0.27 & 21 & 0.47 & 0.21 & 0.19 & 0.19 & 33 & 21 & \\
\hline 11 & 0.04 & 0.05 & 0,05 & 0.05 & 0.04 & 0.05 & 006 & 7 & 0.10 & 0.05 & 111 & 0.12 & 0.07 & 0.07 & 0.09 & 007 & 6 & 0.06 & .08 & 05 & 005 & $a 00^{\circ}$ & $a n$ & 003 & $n \cap k$ & .05 & \\
\hline 12 & 0.01 & 0.02 & 0.01 & 0.01 & 0.01 & 0.02 & 0.02 & 0.15 & 0.05 & 0.01 & 0.01 & 1.09 & 0.01 & 0.01 & 0.01 & 0.01 & 0.02 & 0.01 & 0.01 & 0.01 & 0.01 & 0.01 & 0.01 & 0.01 & 0.01 & .01 & \\
\hline 13 & 0.05 & 0.06 & 006 & 0.07 & 0.06 & 0.11 & 0.08 & 0.10 & 10 & 0.05 & 0.12 & 010 & 1.09 & 08 & (n) & 0.1 & , & 08 & 0 & NG & n & 0.06 & 0.05 & 05 & ne & OK & \\
\hline 14 & 0.02 & 0.02 & 0.02 & 0.02 & 0.02 & 0,03 & 0.03 & 0.02 & 0.03 & 0.03 & 0.03 & 0.03 & 0.03 & 1.04 & 0.03 & 0.03 & 0.03 & 0.03 & 0.03 & 0.04 & 0.04 & 0.04 & 0.03 & 0.03 & 0.04 & 0.04 & \\
\hline 15 & 0.0 & 0.03 & $0.0 j$ & 0.05 & 0.02 & 0.03 & J & 0.03 & 13 & 0.05 & 0.1 & $\sqrt{4}$ & M4 & 04 & 144 & 5 & 5 & Jj & 104 & 14 & 0.04 & 0.04 & 0.03 & Jj & (U) & 14 & \\
\hline 16 & 0.01 & 0.01 & 0.01 & 0.01 & 0.01 & 0.01 & 0.01 & 01 & 0.01 & 0.01 & 0.01 & 001 & 0.01 & 0.02 & 0.01 & 1.01 & 001 & 0.01 & 0.02 & 0.02 & 0.02 & 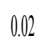 & 0.01 & 001 & 0.02 & 0.02 & \\
\hline 1/ & 0.04 & 0.05 & 0.04 & 0.02 & 0.03 & 0.05 & 0.05 & V) & 0.05 & 0.02 & 0.05 & 0.06 & 0.06 & 0.07 & .00 & 0.03 & 1.02 & 0.05 & .99 & .00 & 0.00 & 0.00 & (U) & 0.05 & 0.08 & 0.06 & \\
\hline 10 & 0.04 & 0.04 & 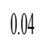 & 0.05 & 0.03 & 0.05 & 0. & 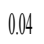 & 0.05 & 0.04 & 0.05 & 0.05 & 0.05 & 0.06 & 0.07 & 0.06 & 005 & 1.06 & 0.07 & 006 & COR & 006 & 0.04 & nal & ane & .06 & \\
\hline 19 & 0.00 & 0.00 & 0.00 & 0.00 & 0.00 & 0,00 & 0.00 & 00 & 0.00 & 0.00 & 0.00 & 0.00 & 0.00 & 0.00 & 0.00 & 0.00 & 0.00 & 0.00 & 1.00 & .00 & 0.00 & 0.00 & 0.00 & 0.00 & 0.00 & 0.00 & \\
\hline 20 & 0.40 & 0.31 & 0.38 & 0.51 & 0.29 & 0.44 & 0.49 & 0.42 & 49 & 0.26 & 0.54 & 0.47 & 0.85 & 1.12 & 0.87 & 0.51 & 48 & 0.57 & 1.01 & 1.32 & 0.32 & 0.32 & 23 & 0.23 & 0.40 & 1.32 & \\
\hline 21 & 0.01 & 0.02 & 0.02 & 0.06 & 0.01 & 0.01 & 0.01 & 12 & 0.01 & 0.01 & 0.02 & 0.01 & 0.01 & 12 & 0.11 & 0.03 & 0.03 & 0.01 & 0.14 & 0.01 & 1.01 & 0.01 & 01 & 0.01 & 0.02 & .01 & \\
\hline L & 0.01 & 0.01 & 0.01 & 0.03 & 0.01 & 0.01 & 0.01 & 01 & 0.02 & 0.01 & 0.01 & 0.01 & 0.02 & 0.03 & 0.02 & 0.01 & 0.01 & 0.01 & 0.03 & 0.01 & 0.01 & 1.01 & 0.00 & 0.00 & 0.01 & 0.01 & \\
\hline 23 & 1.32 & 1.49 & 1.16 & 1.09 & 0.91 & 1.36 & 1.23 & 1.20 & 1.23 & 1.59 & 1.30 & 1.68 & 07 & 1.08 & 1.09 & 1.37 & 30 & 20 & 1.07 & 0.94 & 0.94 & 0.94 & 168 & 0.68 & 1.19 & 0.94 & \\
\hline 24 & 1.32 & 1.49 & 1.16 & 1.09 & 0.91 & 1.36 & 1.23 & 1.20 & 1.23 & 1.59 & 1.30 & 1.68 & 1.07 & 1.08 & 1.09 & 1.37 & 1.30 & 1.20 & 1.07 & 0.94 & 0.94 & 0.94 & 1.68 & 1.68 & 1.19 & 0.94 & \\
\hline 25 & 1.08 & 1.11 & 0.98 & 1.09 & 0.76 & 1.14 & 1.11 & 1.02 & 1.11 & 1.12 & 1.20 & $1.5)$ & 1.51 & 1.02 & 1.41 & 1.22 & (.II) & 1.16 & 1.54 & 1.60 & 1.00 & 1.00 & 14 & 1.14 & 2.01 & 1.60 & \\
\hline 26 & 1.36 & 1.40 & 1.24 & 1.37 & 0.96 & 1.44 & 1.39 & 1.32 & 1.40 & 1.42 & 1.51 & 1.70 & 1.65 & 2.04 & 1.78 & 1.53 & 1.45 & 1.46 & 1.94 & 2.01 & 2.01 & 2.01 & 1.44 & 1.44 & 1.28 & 2.01 & \\
\hline $\mathrm{ma}$ & 8.72 & 8.75 & 8.18 & 8.47 & 6.66 & 8.81 & 8.81 & 8.25 & 8.70 & 8.84 & 9.03 & 10.24 & 9.18 & 6.65 & 9.90 & 9.28 & 8.98 & 8.72 & 10.53 & 9.25 & 9.25 & 9.23 & 7.89 & 6.89 & 9.11 & $8.2 j$ & \\
\hline
\end{tabular}

Fuente: Elaboración propia. 